\title{
Computer Graphics Metafile (CGM) Test Requirements Document (Update)
}

Prepared by

Lynne S. Rosenthal

U.S. DEPARTMENT OF COMMERCE Technology Administration

National Institute of Standards and Technology

Computer Systems Laboratory Gaithersburg, MD 20899

QC 



\section{Computer Graphics Metafile (CGM) Test Requirements Document (Update)}

\section{Prepared by \\ Lynne S. Rosenthal}

U.S. DEPARTMENT OF COMMERCE Technology Administration National Institute of Standards and Technology Computer Systems Laboratory Gaithersburg, MD 20899

April 1993

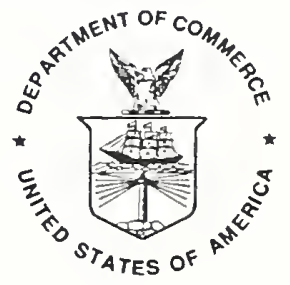

U.S. DEPARTMENT OF COMMERCE Ronald H. Brown, Secretary

NATIONAL INSTITUTE OF STANDARDS AND TECHNOLOGY

Raymond G. Kammer, Acting Director 

1 INTRODUCTION . . . . . . . . . . . . . . . . . . . . . . . 1

1.1 Purpose . . . . . . . . . . . . . . . . . 1

1.2 Background . . . . . . . . . . . . . . . . . 1

1.3 Scope . . . . . . . . . . . . . . . . . . . 1

1.4 Methodology . . . . . . . . . . . . . . . . . . 2

1.5 Overview of new/changed requirements . . . . . . . 2

2 REQUIREMENTS EXTRACTED FROM ANSI/ISO 8632-1:1992 • . . . . 3

2.1 Version 1 CGM requirements . . . . . . . . . . . . 3

2.1.1 Delimiter elements . . . . . . . . . . . 3

2.1.2 Metafile Descriptor elements . . . . . . . 3

2.1.3 Picture descriptor elements . . . . . . . . . 4

2.2 Version 2 CGM requirements . . . . . . . . . . . . 5

2.2.1 Delimiter elements . . . . . . . . . . . 5

2.2.2 Metafile descriptor elements . . . . . . . . 5

2.2.3 Picture descriptor elements . . . . . . . . 6

2.2 .4 Control elements . . . . . . . . . . . 7

2.2.5 Graphical elements . . . . . . . . . . . 8

2.2.6 Attribute elements . . . . . . . . . . . 10

2.2 .7 Segment elements . . . . . . . . . . . 10

2.3 Version 3 CGM requirements . . . . . . . . . . . . 14

2.3.1 Delimiter elements . . . . . . . . . . . . 14

2.3.2 Metafile descriptor elements . . . . . . . . 14

2.3.3 Picture descriptor elements . . . . . . . . 15

2.3 .4 Control elements . . . . . . . . . . . 16

2.3.5 Graphical primitive elements . . . . . . . . 18

2.3.6 Attribute elements . . . . . . . . . . . 21

3 REQUIREMENTS EXTRACTED FROM ANSI/ISO 8632-3:1992 • • • . 27

3.1 Version 1 binary encoding requirements . . . . . . . 27

3.2 Version 2 binary encoding requirements . . . . . . . 27

3.3 Version 3 binary encoding requirements . . . . . . . 30

4 REQUIREMENTS EXTRACTED FROM MIL-D-28003A . . . . . . . . . 36

4.1 Delimiter Elements . . . . . . . . . . . . . 36

4.2 Metafile Descriptor Elements . . . . . . . . . . . 36

4.3 Picture Descriptor Elements . . . . . . . . . . . . 37

4.4 Control Elements . . . . . . . . . . . . . . . 38

4.5 Graphical Primitive Elements . . . . . . . . . . 38

4.6 Attribute Elements . . . . . . . . . . . . . 39

4.7 Segment Elements . . . . . . . . . . . . . 40

4.8 Escape Elements . . . . . . . . . . . . . . . 41

4.9 External Elements . . . . . . . . . . . . . . . . 41

4.10 Generator Requirements . . . . . . . . . . . . . 41

4.11 Interpreter Requirements . . . . . . . . . . . . . 41

Appendix A ELEMENT ORDERING - STATE LIST TABLES . • • . . . . A-1 



\section{INTRODUCTION}

\subsection{Purpose}

This report was prepared by the National Institute of standards and Technology/Computer Systems Laboratory (NIST/CSL) in support of the Computer-aided Acquisition and Logistics Support (CALS) initiative. It represents a NIST/CSL FY93 contract deliverable task to implement CALS conformance Testing services for CGM. In particular, this report updates the CGM Test Requirements Document.

\subsection{Background}

Conformance testing is a way of determining if a CGM product correctly implements the CGM standard and its associated application profile (AP). To meet CALS conformance test requirements, NIST/CSL developed validation test services for testing metafiles and generators for conformance to both the FIPS 128 and the CALS CGM AP, MIL-D-28003. A test service for interpreters is under development.

One of the first tasks in developing the CGM conformance test suite was to produce a test requirements document. This document, produced in FY89, describes the features and functions defined in FIPS 128 and MIL-D-28003 to which an implementation shall be tested for conformance. Since 1990 and the publication of this original test requirements document, both the CGM standard, ANSI/ISO 8632 and the MIL-D-28003 have been revised. The revised CGM standard, ANSI/ISO 8632:1992 and MIL-D-28003A include new functionality and consequently, additional requirements. Due to these changes in the standard and CALS CGM AP, it is necessary to update the conformance test suite and tools.

\section{3 scope}

The objective of a CALS CGM Test Requirements document is to gather together all the requirements that must be satisfied in order for an implementation of the FIPS 128 and CALS CGM AP (e.g., metafile, generator, or interpreter) to be said to be in conformance with the standard and AP.

The original Test Requirements document was published in 1989 as NISTIR 4329. This update supplements the original document and contains only those requirements that result from the new functionality as specified in MIL-D-28003A. It does not repeat the requirements specified in NISTIR 4329. 


\subsection{Methodology}

The CGM functional description, ANSI/ISO 8632-1:1992 was systematically read and all new ${ }^{1}$ requirements relating to the conformance of instances of CGMs were extracted. A similar approach was taken for the CGM binary encoding, ANSI/ISO 86323:1992 and the CALS CGM AP, MIL-D-28003A. Additionally, requirements related to generator and interpreter conformance were extracted from MIL-D-28003A.

Each separate statement of requirements is numbered sequentially and start with a letter, (i.e., "F", "B", or "M") which indicates the source of the requirements. "F" requirements are derived from the CGM Functional Description, Part 1. "B" requirements are derived from the CGM Binary Encoding, Part 3. "M" requirements are derived from the CALS CGM AP, MIL-D-28003A. A citation is given for each statement, identifying the clause or table from which the requirement was extracted.

\section{5 overview of new/changed requirements}

The CGM standard, ANSI/ISO 8632:1992 contains changes due to the following actions:

specification of version 2 CGM, a result of Amendment 1 to ISo $8632: 1987$,

specification of version 3 CGM, a result of Amendment 3 to ISO $8632: 1987$,

approval and publication of defect reports, a result of fixing errors and ambiguities in ISO 8632:1987.

normative inclusion of the formal grammar as specified in Annexes A, B, and C of ISO 8632:1992.

The CALS CGM AP contains additions which reflect the changes to the ANSI/ISO standard as well as some deletions and CALS-related changes.

The remainder of this document is organized as follows:

- Section 2 presents the requirements of the Functional Specification, Part 1 of the CGM standard.

- Section 3 presents the requirements of the Binary Encoding, Part 3 of the CGM standard.

- Section 4 presents the requirements of the revised CALS CGM $A P$, concentrating mainly on the changes between MIL-D-28003 and MIL-D-28003A.

\footnotetext{
${ }^{1}$ New requirements refer to requirements which result from changes or additions between ANSI/ISO 8632:1987 and ANSI/ISO 8632:1992.
} 


\subsection{Version 1 CGM requirements}

F1 Clause $4.3 .4 .5,5.1$

For type string-fixed (SF) parameters, the 7-bit environment is assumed and only 7-bit ISO 2022 controls are allowed.

F2 Clause $4.3 .4 .5,5.1$

ISO 646 is the default character set for string fixed (SF) parameters.

F3 Clause 4.3 .4 .5

In SF parameters, the two character sets $G 0$ and $G 1$ may be accessed by using SI to invoke G1 into positions 2/1 to 7/14 of the 7-bit code chart; and using so to invoke Go into positions $2 / 1$ to $7 / 14$ of the 7 -bit code chart.

F4 Clause $4.3 .4 .5,5.1$

Character set selection for non-graphical text strings, shall be accomplished only through use of embedded Iso 2022 controls.

F5 Clause $4.3 .4 .5,5.1$

Non-graphical text strings shall not be subject to character attributes and controls.

F6 Clause 5.3.14, 5.3.15, 5.7.22

Private values shall not be allowed in any enumerated parameter; e.g., Character coding Announcer, Interior style, and Character set List.

\subsubsection{Delimiter elements}

F7 Clause 4.3 .4 .5

BEGIN METAFILE causes ISO 646 to be designated as the GO set and ISO 8859 to be designated as the GI set.

F8 Clause 5.2.1, 5.2.3

The parameter string for BEGIN METAFILE and BEGIN PICTURE is type SF.

F9 Clause $4.2,5.2 .2$

END METAFILE shall occur exactly once in every CGM.

F10 Clause $4.2,5.2 .4$

BEGIN PICTURE BODY shall occur in all metafiles which contain a BEGIN PICTURE element. (NOTE, this implies that the BEGIN PICTURE BODY must be present in an empty picture). 


\subsubsection{Metafile Descriptor elements}

F11 Clause 4.3

METAFILE VERSION and METAFILE ELEMENT LIST shall occur only once in the Metafile Descriptior.

F12 Clause 5.3.2

The parameter string for METAFILE DESCRIPTION, FONT LIST, and CHARACTER SET LIST sequence tail is type SF.

F13 Clause $4.7 .6,5.3 .10$

The color indices or direct values implied by the local color precision setting shall lie within the range of color values specified by the COLOUR VALUE EXTENT.

F14 Clause $5 \cdot 3 \cdot 10$

The parameters of the COLOUR VALUE EXTENT element depends on the selected color model.

\subsubsection{Picture descriptor elements}

F15 Clause 4.4 .2

The color mode selected by the COLOUR SELECTION MODE element is for the whole picture. 


\subsection{Version 2 CGM requirements}

F16 Clause 0.9

A valid version 1 metafile is also a valid version 2 metafile.

F17 The required sequential relationships between version 2 metafile elements are documented by means of the state diagram in Appendix $A$.

\subsubsection{Delimiter elements}

F18 Clause $4.2,4.6 .11 .1$

Primitives grouped together to form a composite primitive known as a closed figure, is delimited by BEGIN/END FIGURE elements.

F19 Clause $4.2,4.10 .1,4.10 .3$

segments are delimited by BEGIN/END SEGMENT elements.

F20 Clause 5.2 .6

BEGIN SEGMENT is the first element of a segment. All subsequent elements until the next END SEGMENT belong to this segment.

F21 Clause $4.2,4.6 .11 .1$

BEGIN FIGURE and END FIGURE are used to delimit primitives grouped together to form a composite primitive.

F22 Clause 5.2.9

If the current region has not yet been closed by a preceding NEW REGION ELEMENT and if the last point of the last line element is not coincident with the current closure point, then the current subregion is closed by a line segment connecting the las point of the preceding line element to the current closure point.

\subsubsection{Metafile descriptor elements}

F23 Clause $4.3,5.3 .1$

only one metafile version occurrence is allowed.

F24 Clause 4.3 .2 .3

The Version-2 set includes all elements from the drawing-pluscontrol set plus a set of listed elements.

F25 Clause 4.3 .2 .4

The extended-primitives set shall be used to indicate those primitives which are available in version 1, but not defined in ISO 7942 (GKS). 
F26 Clause 4.3 .2 .5

The Version-2-GKSM is a set of Version 2 metafile elements for ISO 7942 GKS) picture capture.

F27 Clause 5.3 .18

The parameters of SEGMENT PRIORITY EXTENT are non-negative, and minimum display priority shall be less than maximum display priority.

F28 Clause 4.10 .2 .1

Global segments are defined in the Metafile Descriptor and are not part of the picture.

\subsubsection{Picture descriptor elements}

F29 Clause 4.4

The following Picture Descriptor elements may appear within the picture body (in v2/3): COLOUR SELECTION MODE, LINE WIDTH SPECIFICATION MODE, MARKER SIZE SPECIFICATION MODE, EDGE WIDTH SPECIFICATION MODE, and INTERIOR STYLE SPECIFICATION MODE.

F30 Clause 4.4 .4

MAXIMUM VDC EXTENT defines an extent which bounds the VDC extent values which may be found in the metafile.

F31 Clause 4.4 .7

The device viewport specifies the region of the device display surface into which the VDC extent is to be mapped.

F32 Clause 4.4.7

VDC-to-Device mapping is determined by the VDC extent, device viewport, and device viewport mapping.

F33 Clause $4.4 .7,5.4 .9$

The DEVICE VIEWPORT SPECIFICATION MODE element selects one of three coordinate systems: by fraction [0.0 to 1.0$]$ of the available display surface; in millimeters times a scale factor; or in physical device coordinates.

F34 Clause $4.4 .7,5.4 .8$

The device viewport is specified in terms of two points on the device display surface at diagonally opposite corners of the rectangle.

F35 Clause $4.4 .7,5.4 .8,5.4 .10$

The VDC-to-Device mapping maps the first point specifying the VDC extent on to the corner of the effective viewport corresponding to the first point specifying the device viewport, and similarly for the second point. The mapping is linear in each dimension. 
F36 Clause 4.4.7

If both device viewport and scaling mode appear in the same metafile, then the last specified is used. If neither appears, then the default values for device viewport take precedence.

F37 Clause $4.4 \cdot 8$

LINE REPRESENTATION, MARKER REPRESENTATION, TEXT REPRESENTATION, FILL REPRESENTATION, and EDGE REPRESENTATION are used to set attribute values in a bundle table.

\section{2 .4 Control elements}

F38 Clause 4.5 .2

There are three different clipping modes for lines, markers, and edges: LINE CLIPPING MODE, MARKER CLIPPING MODE, and EDGE CLIPPING MODE.

F39 Clause 4.5 .2

The required clipping mode is recorded in the metafile with the LINE CLIPPING MODE, MARKER CLIPPING MODE, and EDGE CLIPPING MODE elements.

F40 Clause 4.5 .2

When the CLIP INDICATOR associated with a graphical primitive is 'on', only those parts of a graphical primitive considered inside the effective clip region are rendered on interpretation.

F41 Clause 4.5 .2

clipping may be either 'locus', 'shape', or 'locus then shape'.

F42 Clause $4.5 .2,4.6 .4 .6$

Clipping for fill primitives is consistent with 'shape' clipping.

F43 Clause $4.5 .2,4.7 .3 .2$

Clipping for text primitives is determined by the text precision. For 'string' precision, clipping proceeds on a per string basis as 'locus' clipping. For 'character' precision, clipping proceeds on a per character basis, as 'locus' clipping. For stroke precision, clipping proceeds as 'shape' clipping.

F44 Clause 4.5 .2

Clip rectangles applied to graphical primitives within segments may be subject to transformations in VDC space.

F45 Clause 4.6.11.1.2, 5.5.10

NEW REGION starts a new region. 
F46 Clause 4.6.11.1.2, 5.5.10

NEW REGION may occur at any time during the closed figure construction.

F47 Clause 5.5.10

The first point of the next line element following a NEW REGION element becomes the new closure point, starting a new subregion.

F48 Clause 4.5 .3

The SAVE/RESTORE PRIMITIVE CONTEXT elements are used to save and restore attributes and control elements as collections.

F49 Clause 4.5 .3

The values for attributes controlled by specification or selection modes are saved in the mode in which they were last specified and when restored, the current specification and modes are not changed.

\subsubsection{Graphical elements}

F50 Clause 4.6 .1 .5

For 'locus' clipping of line elements, the mathematical locus of the line is clipped at the intersection with the clip rectangle before shape rendering is applied.

F51 Clause 4.6.1.5

For 'shape' clipping of line elements, the shape of the rendered line is clipped to the intersection with the clip rectangle; $i . e .$, nothing is drawn outside the clip rectangle.

F52 Clause 4.6.1.5

For 'locus then shape' clipping of line elements, the mathematical locus of the line is clipped, and then subsequently the rendered shape of the clipped locus is again clipped.

F53 Clause 4.6 .2 .3

For 'locus' clipping the specifying points of each marker are clipped at the intersection with the clip rectangle before shape rendering is applied. The marker is only visible if its specifying point is within the clip rectangle.

F54 Clause 4.6 .1 .5

For 'shape' clipping, the shape of the rendered marker symbols are clipped to the intersection with the clip rectangle; $i . e$. , nothing is drawn outside the clip rectangle.

F55 Clause 4.6.1.5

For 'locus then shape' clipping, clipping is first applied to the specifying points of each marker, then subsequently the rendered shape of the markers are again clipped. 
F56 Clause 4.6.11

Edge attribute values shall be associated with the edge portions of the complete graphic object.

F57 Clause 4.6.11

The entire fill object is considered a single unit on interpretation.

F58 Clause 4.6 .11

The first point of the first line primitive in a new region is the closure point for that region.

F59 Clause 4.6.11

A closed figure consists of one or more regions.

F60 Clause 4.6.11

A region has a closed boundary, which is either concave, convex, or self intersecting.

F61 Clause 4.6 .11

A fill primitive between BEGIN and END FIGURE closes the last region and begins a new region.

F62 Clause 4.6.11

A closed figure consisting of only line primitives consists of a single region.

F63 Clause 4.6.11.2.1

For fill primitives (except POLYGON SET), the complete edge becomes an explicit boundary portion and edge portion in the closed figure.

F64 Clause 4.6.11.2.1

For line primitives, only those portions become explicit boundary portions and edge portions which would normally be drawn if an interpreter were rendering the line primitive independently in a metafile.

F65 Clause 4.6.11.2.2

Edge attributes are never associated with implicit boundary portions.

F66 Clause 4.6.11.2.3

No boundary or edge portion is created connecting two regions.

F67 Clause 4.6 .11 .3 .2

Each fill primitive contributes a complete region to the figure. 
F68 Clause 5.6 .20

The circular arc center reversed is displayed with current line element attributes.

F69 Clause 5.6 .20

Valid values of CIRCULAR ARC CENTER REVERSED element's vector components are those which produce vectors of non-zero length.

F70 Clause 5.6 .20

Valid values of CIRCULAR ARC CENTER REVERSED element's radius are non-negative VDCs.

F71 Clause $4.6 .11 .1 .2,5.6 .21$

If CONNECTING EDGE is invoked after the last line primitive in an open region, an explicitly boundary portion and edge portion is added.

F72 Clause 5.6 .21

The appearance of the connection edge is determined by the edge attributes.

\subsubsection{Attribute elements}

F73 Clause 4.7 .7

The PICK IDENTIFIER provides a means of identification of primitives within segments. It has no graphical effect.

F74 Clause 5.7 .36

The pick identifier value is associated with all graphical primitive elements within a segment until the next PICK IDENTIFIER.

\subsection{7 segment elements}

F75 Clause 4.10

Graphical objects may be grouped in segments. Graphical primitive elements and attribute elements may be located within segments.

F76 Clause $4.2,4.10 .1,4.10 .3$

Each segment is uniquely identified by a segment identifier.

F77 Clause 4.10 .1

Once a segment is defined, it shall not be changed.

F78 Clause 4.10 .2

Defining a local segment in the picture body automatically includes that segment in the picture's image. Local segments defined in the Picture Descriptor are included in the picture's image when reference from within that picture. 
F79 Clause 4.10 .2

Local segments have no existence beyond the bounds of the picture in which they are defined.

F80 Clause 4.10.2.1

Global segments can be referred to by any of the pictures in the metafile in which they are defined.

F81 Clause 4.10 .2 .1

COPY SEGMENT shall be used to incorporate the global segment into a picture.

F82 Clause 4.10.2.2

Segments are not allowed to be defined in Picture Descriptor state.

F83 Clause 4.10 .2 .3

Within pictures, no elements are allowed that would modify the contents or default appearance of global segments.

F84 Clause 4.10 .2 .3

The only references to global segments within pictures shall be by using the COPY SEGMENT element.

F85 Clause 4.10.4.1

Segment attributes shall be set only after the segment has been opened with the BEGIN SEGMENT element, and before any other type of element.

F86 Clause 4.10.4.1

At the start of a segment, all segment attributes are set to their default values.

F87 Clause 4.10 .4 .2

In all segment elements (e.g., SEGMENT TRANSFORMATION, HIGHLIGHTING, DISPLAY PRIORITY, PICK PRIORITY), the segment identifier must be identical to the identifier of the segment in which the element occurs.

F88 Clause 4.10.4.2

clipping rectangles are not transformed by the segment transformation.

F89 Clause 4.10 .4 .2

Scaling, translation, and rotation of segments are allowed to be defined during segment definition.

F90 Clause 4.10.4.2

A SEGMENT TRANSFORMATION stored in the metafile is applied before the application of the VDC-to-Device mapping. 
F91 Clause 4.10.4.3

The only legal values for segment highlighting are: NORMAL or HIGHLIGHTED.

F92 Clause 4.10 .4 .4

Segments with higher display priorities are displayed as if they are in front of segments with lower display priorities.

F93 Clause $4.10 .4 .4,5.3 .18$

In a metafile, the display priority is an integer in the range defined by the SEGMENT PRIORITY EXTENT.

F94 Clause $4.10 .4 .5,5.3 .18$

In a metafile, the pick priority attribute is an integer in the range defined by the SEGMENT PRIORITY EXTENT.

F95 Clause 4.10 .4 .5

SEGMENT PICK PRIORITY shall cause no graphical effect.

F96 Clause 4.10.5, 5.10.1

The COPY SEGMENT inserts the elements of the referenced segment into the picture at the point of occurrence of the element.

F97 Clause $4.10 .5,5.10 .1$

The copy transformation is applied to graphical objects before they are copied.

F98 Clause 4.10.5, 5.10.2

The inheritance filter controls whether individual attribute values are reapplied to the elements.

F99 Clause $4.10 .5,5.10 .2$

The inheritance filter setting values are either 'segment' or 'state list'.

F100 Clause 4.10 .5

The default inheritance filter setting value is 'segment' for all attributes and controls.

F101 Clause 4.10 .5

The INHERITANCE FILTER is used to select the attributes and controls.

F102 Clause $4.10 .5,5.10 .3$

The legal values for CLIP INHERITANCE are either 'state list' or 'intersection'.

F103 Clause $4.10 .5,5.10 .3$

If the CLIP INHERITANCE value is 'state list', then the clip rectangle associated with primitives in the copied segment is that of the last CLIP RECTANGLE encountered. 
F104 Clause $4.10 .5,5.10 .3$

If the CLIP INHERITANCE value is 'inheritance' and both the modal state list clip indicator and the clip indicator associated with the primitives of the copied segment are 'on', then the resulting clipping boundary is the intersection of the modal state list clip rectangle with the clipping boundary resulting from the application of the copy transformation to the clip rectangle associated with the primitives.

F105 Clause 4.10 .5

Segment Transformations are never applied to clipping boundaries.

F106 Clause 4.10 .5

The default value for CLIP INHERITANCE is 'state list'.

F107 Clause 6

The default values for the following segment attributes are: SEGMENT TRANSFORMATION $=1.0,0.0,0.0,1.0,0.0,0.0 ;$ SEGMENT HIGHLIGHTING $=$ normal; SEGMENT DISPLAY PRIORITY $=0 ;$ SEGMENT PICK PRIORITY $=0$. 


\subsection{Version 3 CGM requirements}

F108 Clause 0.9

A valid version 2 metafile is also a valid version 3 metafile.

F109 The required sequential relationships between metafile elements are documented by means of the state diagram in Appendix A.

\subsubsection{Delimiter elements}

F110 Clause 4.2

A compound path may be used to defined a compound line primitive or for displaying text strings along an arbitrary text path.

F111 Clause 4.2

A compound line is defined by line primitive elements occurring between BEGIN COMPOUND LINE and END COMPOUND LINE.

F112 Clause 4.2

A compound text path is defined by line primitives occurring between BEGIN/END COMPOUND TEXT PATH elements.

F113 Clause 4.2

A compound clipping or shielding region may be defined by line and filled-area elements occurring between BEGIN/END PROTECTION REGION elements.

F114 Clause 4.2

A sequence of TILE and/or BITONAL TILE elements between the BEGIN/END TILE ARRAY delimiters defines a tile array.

\subsubsection{Metafile descriptor elements}

F115 Clause 4.3 .2

The Version-3 set includes all elements from the Version-2 set plus a set of listed elements.

F116 Clause 4.3 .4 .1

The architecture for font resources is defined in Iso 9541.

F117 Clause 5.3.11

For color models RGB and CMYK, the parameters of COLOUR VALUE EXTENT represent an extent which bounds the direct colour values. For color models CIELAB, CIELUV, and RGB-related, the parameters represent the scale and offset that relate each component of a direct color value to the color value of the corresponding color space.

F118 Clause 4.3 .4 .1

The exact name of a font resource is listed in the FONT LIST. 
F119 Clause 4.3.4.1

If the font named in the FONT LIST is not available to the interpreter, the FONT PROPERTIES and GLYPH MAPPING elements contain font descriptive information about the desired fonts and font resources.

F120 Clause 4.3 .4 .2

The font properties which may appear are those in the Minimum Font Description Subset of ISO $9541-2$ and any registered properties.

F121 Clause 4.3 .4 .2

FONT PROPERTIES prioritization indicates which properties take precedence. The higher the priority the greater the importance.

F122 Clause $4 \cdot 3 \cdot 4 \cdot 4$

The GLYPH MAPPING element associates the AFII identifiers with single-byte or multi-byte codes. (AFII is the glyph registrar.)

F123 Clause $4 \cdot 3 \cdot 4.4$

The AFII registered glyphs are accessed through the CGM character set and switching mechanisms.

F124 Clause 5.3.21

The font index in the FONT PROPERTIES element must have been previously defined in the FONT LIST.

F125 Clause 5.3 .22

The character set index used in the GLYPH MAPPING element cannot also be specified in a CHARACTER SET LIST element.

F126 Clause $4.7 .6,5.3 .19$

The COLOUR MODEL element is used to select among the color models: RGB, CIELAB, CIELUV, CMYK, RGB-related.

F127 Clause 5.3.20, Table 12

The calibration data and legal calibration selection values for each color model are specified in Table 12 .

\subsubsection{Picture descriptor elements}

F128 Clause 5.4 .16

The INTERIOR STYLE SPECIFICATION MODE selects the method for specifying geometric aspects associated with filled-area primitives and the transformation behavior of those aspects.

F129 Clause $4.7 .1 .2,5.4 .17$

LINE AND EDGE TYPE DEFINITION specifies the precise definition of the solid/gap sequences which comprise a line or edge type. 
F130 Clause 5.4 .17

LINE AND EDGE TYPE DEFINITION defines a line type or edge type and associates it with an index. The index must be negative.

F131 Clause 5.4 .17

The list of dash elements comprise the definition of the LINE AND EDGE TYPE DEFINITION index. There is at least one element in the list. If there is one element, a solid line is drawn.

F132 Clause 5.4.17

The dash cycle repeat length defines the length of one complete cycle of the dash pattern. The list of dash elements $=$ the dash cycle repeat length.

F133 Clause 5.4.17

The LINE WIDTH SPECIFICATION MODE determines the units of the dash cycle repeat length. LINE AND EDGE TYPE DEFINITION elements may be interleaved with LINE WIDTH SPECIFICATION MODEL elements.

F134 Clause 5.4 .18

HATCH STYLE DEFINITION defines a hatch style and associates it with an index. The index must be negative.

F135 Clause 5.4 .18

The center of the first hatch line is aligned with the FILI REFERENCE POINT. The color of each hatch line is the current fill color. The line width of the hatch lines is = one gap width unit. The direction of the hatch lines is specified by the hatch direction vectors specifier parameter.

F136 Clause 5.4.18

The INTERIOR STYLE SPECIFICATION MODE determines the units of the duty cycle length.

F137 Clause 5.4.19

The GEOMETRIC PATTERN DEFINITION defines a geometric pattern and associates it with an index. The index must be positive and is referenced with the PATTERN INDEX element.

F138 Clause 5.4.19

The two points of the pattern extent of the GEOMETRIC PATTERN DEFINITION element must be distinct points.

\subsubsection{Control elements}

F139 Clause 4.5 .4

Protection regions are identified by an index. If an index is reused, the old definition is deleted and the new protection region indicator takes the initial value 'off'. 
F140 Clause 5.5.13

The region indicator parameter determines how the protection region associated with the given index is used. If the value is: 'off', region is not used; 'clip', region is used for clipping; 'shield', region is used for shielding.

F141 Clause 4.5 .4

Regions which are constructed by line elements are closed by NEW REGION, END PROTECTION REGION, or any filled area elements.

F142 Clause 5.2 .10

A defined region is associated with a region index parameter, by which it may be referenced by the PROTECTION REGION INDICATOR element.

F143 Clause 4.5 .4

If a protection region is used within a segment (i.e., PROTECTION REGION INDICATOR value is 'clip' or 'shield' for region inside segment), it behaves as do clip rectangles with respect to transformations.

F144 Clause 4.5 .4

The effective protection region for clipping and/or shielding, when protection regions are defined, or referenced, within segments, is determined by CLIP INHERITANCE in the same way as for the simpler rectangle clipping.

F145 Clause 4.5 .4

When a protection region is set for clipping, only the portions of the graphical elements inside or on the boundary of the region are drawn.

F146 Clause 4.5 .4

When a protection region is set for shielding, only the portions of the graphical elements outside the region and its boundary are drawn.

F147 Clause 4.5 .4

If clip regions overlap, the effective clip region is the intersection of the individual regions.

F148 Clause 4.5 .4

If several clip and shield regions are in effect simultaneously, only portions of the graphical elements inside or on the boundary of the intersection of all individual clip regions and outside the union of all individual shield regions are drawn.

F149 Clause $4.5 .5,4.7 .3 .2$

The GENERALIZED TEXT PATH MODE selects the method for placing the text along the text path. 
F150 Clause $4.5 .5,4.7 .3 .2$

When GENERALIZED TEXT PATH MODE is off, the text is displayed along the last text path defined by the BEGIN/END COMPOUND PATH elements.

F151 Clause $4.5 .5,4.7 .3 .2$

When GENERALIZED TEXT PATH MODE is non-tangential, the characters are drawn along the text path but the character orientation vectors are not rotated relative to the text path.

F152 Clause $4.5 .5,4.7 .3 .2$

When GENERALIZED TEXT PATH MODE is axis-tangential, the characters are positioned along the text path and the character orientation vectors for each character are rotated by an amount equal to the angle of the tangent to the text path at the character position.

F153 Clause 4.5 .6

The MITRE LIMIT provides a means of specifying how long mitres are to be truncated to form a flat bevel.

F154 Clause 4.5 .6

Mitre length is the distance from the point at which the inside edges of the adjoining line segments meet to the point at which the outside edges meet.

F155 Clause 4.5 .6

When the mitre length divided by the line width exceeds the MITRE LIMIT, then the mitre join is truncated. If truncation results in a flat bevel within the triangular notch of the corresponding bevel join style, then the bevel join style is used.

F156 Clause 4.5 .7

The TRANSPARENT CELL COLOUR allows a given value of a cell color specifier to be transparent. (This element can apply to the CELL ARRAY, TILE, or BITONAL TILE elements or filling patterns defined by PATTERN TABLE elements)

F157 Clause 4.5 .7

To invoke transparency, the cell color specifier shall be defined as transparent prior to the occurrence of the affected element in the metafile.

F158 Clause 4.5 .7

The rendering of any element affected by TRANSPARENT CELL COLOUR shall not involve more than one distinct value of cell color specifier simultaneously being designated as transparent.

\subsubsection{Graphical primitive elements}


F159 Clause 4.6

TEXT, RESTRICTED TEXT, and APPEND TEXT elements and related text attribute elements are defined in the current VDC space. They are affected by changes to the Virtual Device coordinate format.

F160 Clause 4.6.1.1

The curve (line) element, HYPERBOLIC ARC generates the conic arc as a hyperbolic arc.

F161 Clause 4.6.1.1

The curve (line) element, PARABOLIC ARC generates the conic arc as a parabolic arc.

F162 Clause 4.6.1.1

The spline curve (line) element, NON-UNIFORM B-SPLINE, generates a Non-Uniform B-Spline curve.

F163 Clause 4.6.1.1

The spline curve (line) element, NON-UNIFORM RATIONAL BSPLINE, generates a Non-Uniform Rational B-Spline (NURBS) curve.

F164 Clause 4.6.1.1

The spline curve (line) element, POLYBEZIER, generates a sequence of one or more cubic Bezier curves.

F165 Clause 4.6 .1 .2

When using compound line, a line consisting of a number of distinct elements, such as straight lines and arcs, is treated as a single element.

F166 Clause 4.6.1.2

Line attributes may not change within a compound line.

F167 Clause 4.6.4.7

If the INTERIOR STYLE SPECIFICATION MODE is absolute the geometric aspects of fill interiors are subject to all transformations.

F168 Clause 4.6 .5 .2

Between the BEGIN/END TILE ARRAY elements are a series of equally sized individual tiles which form a contiguous rectangular block.

F169 Clause 4.6.5.2

The first tile, with tile identifier 1 , is placed at the position parameter of the BEGIN TILE ARRAY element. Subsequent tiles are placed in order first in the cell path direction, then in the line progression direction. Tiles are numbered sequentially (as they are placed). 
F170 Clause $4 \cdot 6 \cdot 5.2$

BITONAL TILE defines a two colored, rectangular raster image of either uncompressed or compressed data.

F171 Clause $4 \cdot 6 \cdot 5.2$

The colors of BITONAL TILE are the values associated with indexes 0 and 1 .

F172 Clause $4 \cdot 6 \cdot 5.2$

TILE defines a bitonal or full color rectangular raster image of either uncompressed or compressed data.

F173 Clause $4 \cdot 6 \cdot 5.2$

The colors associated with the cells of TILE element are either direct or indexed color and specified according to the applicable color precisions and modes.

F174 Clause 4.6 .5 .2

TILE and BITONAL TILE contain no positioning or dimensioning information. They contain only raster data and any applicable control parameters.

F175 Clause $4 \cdot 6 \cdot 5.2$

The parameters of BEGIN TILE ARRAY apply to the collection of tiles and uniformly to each tile in the collection.

F176 Clause 5.2.16

The parameters of BEGIN TILE ARRAY define the tile. The point specified by the position parameter is used to place the first tile. The cell path direction is the direction of progression of successive cells along a line relative to the VDC $x$-axis. The line progression is the direction of progression of successive cell lines and is relative to the cell path direction. The values of cell size and number of cells/tile in path direction define the tile size in the cell path direction. The values of cell size and number of cells/tile in line direction define the tile size in the line progression direction.

F177 Clause 4.6 .5 .2

The cell color data of the tile elements is a compressed stream of cell color specifiers.

F178 Clause 4.6.5.2, 5.2.16

The position of the actual image data may be offset such that there is a border of undefined data surrounding the actual image. This undefined data is included in the encoding of the tiles which overlap the border and the defined image.

F179 Clause 4.6 .8

The start and end of the hyperbolic arc are parmeterized by vectors from the center. 
F180 Clause 4.6 .8

The canonical hyperbolic arc is defined by $x^{*} x-y^{*} y=1$ and passes through the point $u 1$ and at ul the tangent to the hyperbola is parallel to $\mathrm{u} 2$. The hyperbola has center at the origin.

F181 Clause 4.6 .9

The general parabolic arc is parameterized by the endpoints of the arc and the intersection of the tangents to the arc at the endpoints.

F182 Clause $4 \cdot 6 \cdot 10.1$

The non-uniform B-spline is parameterized by a spline order, list of knots, a list of control points, and parameter range limits defining the curve section to be drawn.

F183 Clause 4.6 .10 .1

The non-uniform rational B-spline is parameterized by a spline order, list of knots, list of control points, list of weights associated with the control points, and parameter range limits defining the curve section to be drawn.

F184 Clause $4 \cdot 6 \cdot 10.2$

The polybezier is parameterized by a list of points and an indicator specifying the degree of continuity between the individual Bezier curves. If there are $n(n>=1)$ curves, then the data list will contain $4 \mathrm{n}$ points if continuity is discontinuous or $3 n+1$ points if continuity is continuous.

F185 Clause 4.6 .12

A symbol created by POLYSYMBOL is sized and oriented according to the symbol attributes and placed with its reference point coinciding with the specified position points.

F186 Clause 4.6 .12 .2

The selection, sizing, and placement of symbols is specified by the symbol attribute elements.

\subsubsection{Attribute elements}

F187 Clause 4.7 .1 .2

For LINE CAP unspecified, any implementation dependent treatment is acceptable.

F188 Clause 4.7 .1 .2

For LINE CAP butt, the line is squared off at the endpoint; there is no projection beyond the endpoint.

F189 Clause 4.7 .1 .2

For LINE CAP round, a semicircular arc with diameter equal to the line width is drawn around the endpoint and filled in. The line projects beyond the endpoint. 
F190 Clause 4.7 .1 .2

For LINE CAP projecting square, the line is squared off at a distance equal to half the line width beyond the endpoint.

F191 Clause 4.7.1.2

For LINE CAP triangle, a cap is added to the line which is an equilateral triangle whose side equals the line width.

F192 Clause 4.7.1.2

LINE CAP is applicable to open endpoints of line elements or to interior endpoints.

F193 Clause 4.7 .1 .2

The interior caps must either match the caps on the open endpoints or be implementation dependent.

F194 Clause 4.7.1.2

For LINE JOIN unspecified, any implementation dependent treatment is acceptable.

F195 Clause 4.7 .1 .2

For LINE JOIN mitre, the outer edges of the two adjoining line segments are extended until they meet at a point.

F196 Clause 4.7 .1 .2

For LINE JOIN round, a circular arc with diameter equal to the line width is drawn around the vertex between the adjoining segments and is filled in, producing a round corner.

F197 Clause 4.7 .1 .2

For LINE JOIN bevel, the adjoining line segments are terminated with a butt cap and the resulting triangular notch is filled in.

F198 Clause 4.7 .1 .2

Line caps and line joins behave as does line width with respect to transformation.

F199 Clause 4.7.1.2

For LINE TYPE CONTINUATION unspecified, no special treatment is required.

F200 Clause 4.7.1.2

For LINE TYPE CONTINUATION continue, the style is continued without interruption across vertices.

F201 Clause 4.7.1.2

For LINE TYPE CONTINUATION restart, the style is restarted at each vertex. 
F202 Clause 4.7.1.2

For LINE TYPE CONTINUATION adaptive continue, the style is continued, but each vertex must be inked including vertices at the ends of the line primitive which might otherwise not be drawn because of a non-solid line type.

F203 Clause 4.7 .1 .2

LINE TYPE INITIAL OFFSET controls how much of the first cycle of a non-solid line type to omit before drawing commences for a line primitive. It is specified as a fraction of one full cycle.

F204 Clause 4.7 .3 .1

For RESTRICTED TEXT TYPE basic, the string specified is constrained not to exceed the text restriction box.

F205 Clause 4.7.3.1

For RESTRICTED TEXT TYPE boxed, the baseline to capline distance of the text string exactly fills the text restriction box in the vertical direction and the width of the string exactly fits the box in the horizontal direction.

F206 Clause 4.7.3.1

For RESTRICTED TEXT TYPE isotropic, the text string is displayed as large as possible within the text restriction box without altering the ratio of the height to the width of the string.

F207 Clause 4.7.3.1

For RESTRICTED TEXT TYPE justified, the text string exactly fits the text restriction box in the width direction without changing the proportions of the characters.

F208 Clause 5.7.22

Legal values for INTERIOR STYLE are; hollow, solid, pattern, hatch, empty, geometric pattern, and interpolated.

F209 Clause 4.7.4.3

The color and line type of the lines in the hatch may be defined as part of the hatch style definition using the HATCH STYLE DEFINITION element.

F210 Clause 4.7 .4 .3

Changing the definition of an already defined hatch index shall have no retroactive or dynamic effects.

F211 Clause $4 \cdot 7 \cdot 4 \cdot 3 \cdot 2$

Interpolated interior parallel is a multi-stage style. Each stage is semi-infinite band bounded by two parallel lines. A reference color is defined on each parallel line. Color is constant within the band and equal to the linear interpolant of the reference colors. Color for outermost bands is 
constant and equal to the corresponding outer-most reference colors.

F212 Clause 4.7.4.3.2

Interpolated interior elliptical is a multi-stage style. Each style is an elliptical annulus with a reference color defined on each of the inner and outer bounding ellipses. Colors are constant along ellipses which are concentric to the reference ellipse.

F213 Clause $4.7 .4 \cdot 3 \cdot 2$

For interpolated interior triangular, colors are associated with three points defining a triangle.

F214 Clause 5.7 .43

For the INTERPOLATED INTERIOR element, the values of the scalars of the reference geometry must produce distinct (noncoincident) geometry reference points.

F215 Clause 4.7 .4 .4

EDGE CAP specifies the appearance of the endpoints of edges. The supported styles and definitions are the same as for the LINE CAP element.

F216 Clause 4.7 .4 .4

EDGE JOIN specifies the appearance of edges at the vertices of filled-area elements or at junctions between distinct elements in compound filled area elements. The supported styles and their definitions are as for the LINE JOIN element.

F217 Clause 4.7 .4 .4

EDGE TYPE CONTINUATION provides control of the behavior of non-solid edge types at interior vertices and junctions of the edges of filled-area elements. The supported styles and their definitions are as for the LINE TYPE CONTINUATION element.

F218 Clause 4.7 .4 .4

EDGE TYPE INITIAL OFFSET controls how much of the first cycle of a non-solid line type to omit before drawing commences for a line primitive. It is specified as a fraction of one full cycle.

F219 Clause 4.7 .5

Geometric information related to line width, line type, edge width, edge type, marker size and fill interiors is specified with modes: absolute, scaled, fractional, and $\mathrm{mm}$.

F220 Clause 4.7 .5

In absolute mode, the associated aspects are conceptually rendered in VDC space before it applies any associated transformations. 
F221 Clause 4.7 .5

Scaled mode is completely device and interpreter independent neither the final displayed sizes nor their relationship to the rest of the displayed picture are precisely controllable.

F222 Clause 4.7 .5

Fractional mode precisely specifies the sizes according to their relationship to the rest of the picture but not in terms of actual physical measurements.

F223 Clause 4.7 .5

MM mode precisely specifies the sizes in terms of their actual physical measurements which remain invariant as display size varies.

F224 Clause 4.7 .6

Color models define a color coordinate system and subspace within which each color is represented by a point

F225 Clause 4.7 .6

The meaning of each color space is defined by the transformation necessary to convert a color specification expressed in a reference color space to or from the specification of the same color in the CGM color space (color calibration).

F226 Clause 4.7 .6

The reference color space is normalized such that the $Y$ tristimulus value is 1 for the reference white.

F227 Clause 4.7 .6

The reference white value is the only calibration data applicable to the CIELAB and CIELUV color spaces.

F228 Clause 4.7 .6

Calibration data for the RGB color space consists of a $3 \times 3$ matrix specifying the position of the RGB primaries in CIEXYZ space.

F229 Clause 4.7 .6

The calibration data for the CMYK color space consists of CMYK grid locations and corresponding CIEXYZ values.

F230 Clause 4.7 .8

The path of a compound text path consists of a number of distinct elements which serve as a reference path for laying out subsequent text strings.

F231 Clause 4.7 .8

If two adjacent line segments of a compound text path are not contiguous, then the path includes the straight line segment joining these two points. 
F232 Clause 4.7 .8

Each glyph in a text string is placed with its reference point on the compound text path according to the alignment.

F233 Clause $4.7 .9,5.7 .48$

The value of the symbol library index of the SYMBOL LIBRARY INDEX element must correspond to a value already specified in the SYMBOL LIBRARY LIST element.

F234 Clause $4.7 .9,5.7 .51$

For the SYMBOL ORIENTATION element, the symbol up vector and the symbol base vector must be non-collinear and have positive length. 


\subsection{Version 1 binary encoding requirements}

B1: Clause $6,7.6$

Individual run-lengths in CELL ARRAY shall not be constrained to start on word boundaries.

B2: Clause 4.4

When partitioning elements, only the beginnings of elements, and not the start of each partition, is constrained to start on word boundaries.

B3: Table 8

The Character Expansion Factor can be 0 or any positive real number.

B4: Annex C

NOOP is legal in Metafile Element List.

B5: Clause 5.3

The character count of string type parameters counts octets, not complete character codes.

B6: Clause $7.3,7.7$

Private values shall not be allowed in any enumerated parameter; e.g., Character Coding Announcer, Interior style, and Character set List.

\subsection{Version 2 binary encoding requirements}

B7 Table 1

When DEVICE VIEWPORT SPECIFICATION MODE is 'fraction of display surface', the parameter type VC is real.

B8 Table 1

When DEVICE VIEWPORT SPECIFICATION MODE is 'millimetres with scale factor' or 'physical device coordinates', the parameter type VC is integer.

B9 Table 1

The abstract parameter type VC, a single VC value, is a either real or integer depending on the DEVICE VIEWPORT SPECIFICATION MODE element. If the mode is 'fraction of display surface', the value is real; otherwise, the value is integer.

B10 Table 3

BEGIN SEGMENT has 1 parameter, P1 which is a unique segment identifier. 
B11 Table 4

NAME PRECISION has 1 parameter with precision values of 8,16 , 24 , or 32 .

B12 Table 4

SCALING MODE parameter is always encoded as Floating Point, regardless of the values of the fixed/floating flag of REAL PRECISION.

B13 Table 5

The valid values of DEVICE VIEWPORT SPECIFICATION MODE are fraction of drawing surface, millimetres with scale factor, and physical device coordinates.

B14 Table 5

DEVICE VIEWPORT SPECIFICATION MODE parameter is always encoded as Floating Point, regardless of the values of the fixed/floating flag of REAL PRECISION.

B15 Table 5

DEVICE VIEWPORT MAPPING has 3 enumerated parameters: P1 values are: 'not forced' or 'forced'; P2 values are: 'left', 'center', or 'right'; and P3 values are: 'bottom', 'center', or 'top'.

B16 Table 5

LINE REPRESENTATION has 4 parameters, P2 has standardized values 1-5. The parameters correspond to the bundle table entries.

B17 Table 5

MARKER REPRESENTATION has 4 parameters, P2 has standardized values 1-5. The parameters correspond to the bundle table entries.

B18 Table 5

TEXT REPRESENTATION has 6 parameters. The parameters correspond to the bundle table entries.

B19 Table 5

FILL REPRESENTATION has 5 parameters, P2 is an enumerated style, $P 4$ has standardized values 1-6. The parameters correspond to the bundle table entries.

B20 Table 5

EDGE REPRESENTATION has 4 parameters, P2 has standardized values 1-5. The parameters correspond to the bundle table entries.

B21 Table 6

LINE CLIPPING MODE has 1 enumerated parameter, valid values are: 'locus', 'shape', and 'locus then shape'. 
B22 Table 6

MARKER CLIPPING MODE has 1 enumerated parameter, valid values are: 'locus', 'shape', and 'locus then shape'.

B23 Table 6

EDGE CLIPPING MODE has 1 enumerated parameter, valid values are: 'locus', 'shape', and 'locus then shape'.

B24 Table 6

NEW REGION has no parameters.

B25 Table 6

The P1 parameter of SAVE PRIMITIVE CONTEXT is the unique context name.

B26 Table 6

The P1 parameter of RESTORE PRIMITIVE CONTEXT is a context name that corresponds to name in SAVE PRIMITIVE CONTEXT.

B27 Table 7

CIRCULAR ARC CENTRE REVERSED has 6 parameters, a point and 5 vdc values.

B28 Table 7

CONNECTING EDGE has no parameters.

B29 Table 8

PICK IDENTIFIER has 1 parameter.

B30 Clause 7.7

For line types, marker types, and edge types, registered values greater than 5 are reserved for registration. For Hatch indices, values above 6 are reserved for registration.

B31 Table 11

COPY SEGMENT has 3 parameters; an identifier, 6 values of the transformation matrix, and an enumerated value: 'no' or 'yes'.

B32 Table 11

INHERITANCE FILTER has 2 parameters; PI is a list of up to 70 attribute or group designators, P2 is an enumerated value: 'state list' or 'segment'.

B33 Table 11

CLIP INHERITANCE has 1 parameter with the enumerated value:

'state list' or 'intersection'.

B34 Table 11

SEGMENT TRANSFORMATION has 2 parameters; an identifier, and 6 values of the transformation matrix. 
B35 Table 11

SEGMENT HIGHLIGHTING has 2 parameters; an identifier and the enumerated value: 'normal' or 'highlighted'.

B36 Table 11

SEGMENT DISPLAY PRIORITY has 2 parameters; an identifier and the display priority.

B37 Table 11

The default segment display priority is equal to the minimum segment priority value.

B38 Table 11

SEGMENT PICK PRIORITY has 2 parameters; an identifier and the pick priority.

B39 Table 11

The default segment pick priority is equal to the minimum segment pick value.

B40 Clause 8

The default NAME PRECISION is 16 bits.

\subsection{Version 3 binary encoding requirements}

B41 Table 1, note 15

The bitstream (BS) data type is encoded as a stream of binary digits (bits) packed in 16-bit unsigned integers.

B42 Table 1, note 16

The abstract parameter type $C D$ is a 3-tuple or 4-tuple of color coordinates depending on the COLOUR MODEL.

B43 Table 3

BEGIN COMPOUND PATH has 1 enumerated parameter with value:

'text path' or 'compound line'.

B44 Table 3

BEGIN PROTECTION REGION has 1 parameter, a region index.

B45 Table 3

BEGIN TILE ARRAY has 13 parameters; a point position, enumerated cell path direction $(0,90,180,270$ degrees), enumerated line progression direction $(90,270)$, number of tiles in path direction, number of tiles in line direction, number of cells/tile in path and line directions, cell size in path and line directions, image offset in path and line directions, image size in path and line directions.

B46 Table 4

Each character is stored in 1 or more consecutive octets, depending upon the coding of the character set. 
B47 Table 4

The COLOUR VALUE EXTENT element provides the mapping between a direct color component and the corresponding real value.

B48 Table 4

For RGB or CMYK, the COLOUR VALUE EXTENT has 2 parameters, the minimum and maximum color values.

B49 Table 4

For CIELAB or CIELUV, the COLOUR VALUE EXTENT has 3 parameters; the scale and offset pair for the first, second and third components.

B50 Table 4

The standardized COLOUR MODEL values are RGB, CIELAB, CIELUV, and CMYK.

B51 Table 4

Color model values greater than 5 are reserved for registration.

B52 Table 4

COLOUR CALIBRATION has 4 parameters; reference white value for the X, Y, Z components; and the calibration data whose format depends on the color model.

B53 Table 4

FONT PROPERTIES has 4-tuple parameters containing the property indicator, property value type, property value, and priority.

B54 Table 4

Valid values for the property indicator are $1-6$.

B55 Table 4

Property value values must be used in correct association with the property value type and property name.

B56 Table 4

GLYPH MAPPING has 5 parameter values: an index; enumerated basis set character set type; string of sequence tail; number of octets per code; and list of the glyph name pairs.

B57 Table 4

SYMBOL IIBRARY LIST has a variable parameter list depending on the number of library names. The number of parameters equals the number of names in the list.

B58 Table 5

The metric scale factor of the SCALING MODE and DEVICE VIEWPORT SPECIFICATION MODE elements must always be coded with floating point reals. 
B59 Table 5

The parameter range for the LINE WIDTH SPECIFICATION MODE is $\{0 . .3\}$, with values: 'absolute', 'scaled', 'fractional', and 'mm'.

B60 Table 5

The parameter range for the MARKER WIDTH SPECIFICATION MODE is $\{0 . .3\}$, with values: 'absolute', 'scaled', 'fractional', and ' $m m^{\prime}$.

B61 Table 5

The parameter range for the EDGE WIDTH SPECIFICATION MODE is $\{0: .3\}$, with values: 'absolute', 'scaled', 'fractional', and 'mm'.

B62 Table 5

INTERIOR STYLE SPECIFICATION MODE has 1 enumerated parameter with values: 'absolute', 'scaled', 'fractional', or 'mm'. Version $1 / 2$ the style is limited to 'absolute'.

\section{B63 Table 5}

The parameter list of LINE AND EDGE TYPE DEFINITION is variable. The index (line type) parameter is always negative.

B64 Table 5

The parameter list of HATCH STYLE DEFINITION contains the hatch index; an enumerated style indicator with values: 'parallel' or 'cross hatch'; the hatch direction for the $x$ and $y$ component in the first and second directions; a real duty cycle length; the number ' $n$ ' of hatch lines; list of ' $n$ ' gap widths; and list of ' $n$ ' line types.

B65 Table 5

The HATCH STYLE DEFINITION has a variable parameter list. The index (hatch index) values are always negative and the style indicator is an enumerated value: 'parallel' or 'cross hatch'.

B66 Table 5

The GEOMETRIC PATTERN DEFINITION has 4 parameters: an index; segment identifier; first corner point; and second corner point.

B67 Table 6

AUXILIARY COLOUR values are either a 3-tuple or 4-tuple of direct color components, depending on the color model.

B68 Table 6

PROTECTION REGION INDICATOR has 2 parameters: an index and a region indicator with values: 'off', 'clip', and 'shield'. 
Table 6

GENERALIZED TEXT PATH MODE has 1 enumerated parameter with values: 'off', 'non-tangential', and 'axis tangential'.

B70 Table 6

The MITRE LIMIT is parameter is a non-negative real.

B71 Table 7

HYPERBOLIC ARC has 7 parameters to describe the arc: P1..P3 are points; and P4..P7 are vdc values.

B72 Table 7

PARABOLIC ARC has 3 parameters to describe the arc: tangent intersection; start; and end points.

B73 Table 7

NON-UNIFORM B-SPLINE has a variable parameter list. The first 2 parameters are always the spline order and number of control points.

B74 Table 7

NON-UNIFORM RATIONAL B-SPLINE has a variable parameter list. The first 2 parameters are always the spline order and number of control points.

B75 Table 7

POLYBEZIER has a variable parameter list: values for Pl are 'discontinuous', 'continuous', and 'smooth'. The other parameters are a list of point sequences.

B76 Table 7

SYMBOL has 2 parameters: a position point and the symbol index.

B77 Table 7

TILE has 4 parameters: a tile identifier: an index (0..6) indicating the compression type; the cell color precision; and the compressed cell color specifiers.

B78 Table 7

The compression type values $0-6$ are registered; values greater than 6 are reserved for registration.

B79 Table 7

The cell color precision values for TILE are the same as for the local color precision of CELL ARRAY.

B80 Table 8

If the LINE WIDTH specification mode is absolute, the line width specifier is vdc; otherwise the specifier is real. 
B81 Table 8

If the MARKER SIZE specification mode is absolute, the line width specifier is vdc; otherwise the specifier is real.

B82 Table 8

If the EDGE WIDTH specification mode is absolute, the line width specifier is vdc; otherwise the specifier is real.

B83 Table 8

The parameter list for LINE AND EDGE TYPE DEFINITION is variable; containing the line type index, the dash cycle length, and ' $n$ ' parameters of dash elements.

B8 4 Table 8

LINE CAP has 2 parameters: the indicator with standardized values $1 . .5$; and the enumerated dash cap indicator with values 'unspecified' or 'match'.

B85 Table 8

The LINE JOIN parameter is an indicator with standardized values $1 \ldots 4$.

B86 Table 8

The LINE TYPE CONTINUATION parameter has standardized values 1..4. Values greater than 4 are reserved for registration.

B87 Table 8

The LINE TYPE INITIAL OFFSET parameter is real.

B88 Table 8

The TEXT SCORE TYPE parameter has standardized values $1 . .4$ for score type and 0 or 1 for score indicator.

B89 Table 8

The RESTRICTED TEXT TYPE parameter has standardized values 1 .. 4 .

B90 Table 8

The variable parameter list of INTERPOLATED INTERIOR DEFINITION contains the style with standardized values 1..3; the reference geometry; the number of ' $m$ ' stages; array of ' $m$ ' stage designators; and array of color specifiers.

B91 Table 8

EDGE CAP has 2 parameters: the indicator with standardized values 1..5; and the enumerated dash cap indicator with values: 'unspecified' or 'match'.

B92 Table 8

The EDGE JOIN parameter is an indicator with standardized values 1..4. Values greater than 4 are reserved for registration. 
B93 Table 8

The EDGE TYPE CONTINUATION parameter has standardized values 1..4. Values greater than 4 are reserved for registration.

B94 Table 8

The EDGE TYPE INITIAL OFFSET parameter is real.

B95 Table 8

The SYMBOL LIBRARY INDEX parameter is an index which corresponds to an entry in the symbol table.

B96 Table 8

The SYMBOL COLOUR parameter indicates the symbol color.

B97 Table 8

SYMBOL SIZE has 3 parameters: the enumerated scale indicator with values: 'height', 'width', or 'both'; symbol height; and symbol width.

B98 Table 8

SYMBOL ORIENTATION has 4 vdc parameters: the $x$ and $y$ up vector components; and the $x$ and $y$ base vector components. 
4 REQUIREMENTS EXTRACTED FROM MIL-D-28003A

\subsection{Delimiter Elements}

M1 BEGIN SEGMENT

The number of simultaneously defined segments is limited to 256. This number of levels of nesting of segments is limited to 4 .

M2 BEGIN/END COMPOUND LINE

The number of contributing elements is limited to 32 .

M3 END TILE ARRAY

Tile size is limited to 1048576 compressed color specifiers.

M4 END TILE ARRAY

The number of tiles is limited to 256 .

\subsection{Metafile Descriptor Elements}

M5 METAFILE VERSION

Any of the version values, "1" "2", or "3" shall be contained in the metafile.

M6 METAFILE VERSION

The metafile version shall appear only once in a metafile.

M7 METAFILE DESCRIPTION

The element string must contain the phrase "MIL-D28003A/BASIC-1" followed by one of the strings " (the null string), ".0", ".1", or ".2".

M8 METAFILE DESCRIPTION

If Type 0 is encountered, the metafile is monochrome and shall be capable of interpreting only monochrome.

M9 METAFILE DESCRIPTION

If Type 1 is encountered, the metafile is grayscale and shall

be capable of interpreting monochrome and grayscale.

M10 METAFILE DESCRIPTION

If Type 2 is encountered, the metafile is color and shall be capable of interpreting monochrome, grayscale, and color.

M11 METAFILE DEFAULTS REPLACEMENT

This element shall not be partitioned, nor shall elements within the METAFILE DEFAULTS REPLACEMENT.

M12 Order of Metafile Descriptor Elements

The first three Metafile Descriptor elements are: METAFILE VERSION, METAFILE ELEMENT LIST, METAFILE DESCRIPTION. 
M13 FONT LIST

Up to 32 simultaneous fonts are supported with names selected from table IX and $\mathrm{X}$ in MIL-D-28003A.

M14 FONT LIST

The font names "HERSHEY' is an acceptable substitution for "HERSHEY/".

M15 FONT LIST

The font names are case insensitive (i.e., upper or lower case is not significant).

M16 FONT LIST

Substitution of the named fonts with fonts which are metrically equivalent fonts is allowed.

M17 MAXIMUM COLOUR INDEX

The MAXIMUM COLOUR INDEX must correspond to the color level (i.e., 0,1 , or 2).

M18 MAXIMUM COLOUR INDEX

The parameter is limited to 0-255 for color metafiles; 0-15

for grayscale metafiles, and 0-1 for monochrome metafiles.

M19 NAME PRECISION

The parameter value shall be limited to either 8 or 16 bits.

M20 Version 3 elements

The following elements are not allowed: COLOUR MODEL, COLOUR

CALIBRATION, FONT PROPERTIES, GLYPH MAPPING, SYMBOL LIBRARY LIST.

\subsection{Picture Descriptor Elements}

M21 COLOUR SELECTION MODE

only a single value of color selection mode, 0 or 1 , may appear in each picture. The color mode may not be changed within a picture.

M22 Version 2 elements

The following elements are not allowed: SET LINE REPRESENTATION, SET MARKER REPRESENTATION, SET TEXT REPRESENTATION, SET FILL REPRESENTATION, SET EDGE REPRESENTATION, DEVICE VIEWPORT, DEVICE VIEWPORT MAPPING, DEVICE VIEWPORT SPECIFICATION MODE.

M23 LINE and EDGE TYPE DEFINITION

At most 16 user line types shall be specified simultaneously. The number of entries in the dash gap list parameter shall not exceed 8 . 
M24 HATCH STYLE DEFINITION

At most 16 user hatch styles shall be specified simultaneously. The number of entries in the gaps list parameter shall not exceed 8 .

M25 Version 3 elements

The following elements are not allowed: GEOMETRIC PATTERN DEFINITION.

\subsection{Control Elements}

M26 Required Version 2 and 3 elements

The following elements must be present in version 2 or version 3 metafiles: LINE CLIP MODE, MARKER CLIP MODE, EDGE CLIP MODE.

M27 LINE CLIP MODE

The default value is 1 (shape). The basic values are $1 . .2$.

M28 MARKER CLIP MODE

The default value is 1 (shape). The basic values are $1 . .2$.

M29 EDGE CLIP MODE

The default value is 1 (shape). The basic values are $1 \ldots 2$.

M30 Version 2 elements

The following elements are not allowed: SAVE PRIMITIVE CONTEXT, RESTORE PRIMITIVE CONTEXT.

M31 Version 3 elements

The following elements are not allowed: PROTECTION REGION INDICATOR, GENERALIZED TEXT PATH MODE.

\subsection{Graphical Primitive Elements}

M32 TEXT, APPEND TEXT, RESTRICTED TEXT

Control characters (codes 1-31 and 128-159) are prohibited, but NUL (code 0 ) is allowed, in graphical text strings except as required to implement permissible character set switching mechanisms.

M33 closed figure

The number of contributing elements is limited to 32 .

M34 POLYBEZIER

The number of bezier segments shall not exceed 256 .

M35 TILE, BITONAL TILE

The basic values of the compression type parameter shall be limited to 0-6. 
M3 6 NON UNIFORM B-SPLINE, NON UNIFORM RATIONAL B-SPLINE

The basic values for order are: 2.7 . The number of control points shall be <or $=1024$.

\subsection{Attribute Elements}

M37. LINE TYPE

Basic values are the standardized values $1-5$ and registered values 6-15. Private values (i.e. those defined in MIL-D28003) are not allowed.

M38 LINE WIDTH

The width shall not exceed $10 \%$ of the drawing size, which is defined as the shortest side of the VDC Extent. Wider lines shall be rendered as filled areas.

M39 HATCH INDEX

Basic values are the standardized values 1-6. Private values (i.e., those defined in MIL-D-28003) are not allowed.

M40 EDGE WIDTH

The width shall not exceed $10 \%$ of the drawing size, which is defined as the shortest side of the VDC Extent. Wider lines shall be rendered as filled areas.

M41 EDGE

Drawn edges of filled-area elements shall be centered on the ideal mathematically-defined edge of the area.

M42 TEXT FONT INDEX

Every referenced font index shall correspond to a defined entry in the font list.

M43 CHARACTER SET INDEX

Every referenced character set index shall correspond to a defined entry in the character set list.

M44 ALTERNATE CHARACTER SET INDEX

Every referenced alternate character set index shall correspond to a defined entry in the character set list.

M45 COLOUR TABLE

The starting color index shall correspond to the color level $(0,1,2)$ such that the index range is: 0-255 for color metafiles, 0-15 for grayscale metafiles, and 0-1 for monochrome metafiles.

M46 PICK IDENTIFIER

This element has no graphical effect. It may be ignored by interpreters. 
M47 LINE CAP

Basic values for line cap indicator are 1-5. Basic values for dash cap indicator are 1-3.

M48 LINE JOIN

Basic values for the line join indicator are 1-4.

M49 LINE TYPE CONTINUATION

Basic values for continuation mode are $1-4$.

M50 LINE TYPE INITIAL OFFSET

Basic values are $0.0-1.0$ (inclusive).

M51 EDGE CAP

Basic values for edge cap indicator are 1-5. Basic values for dash cap indicator are 1-3.

M52 EDGE JOIN

Basic values for the edge join indicator are 1-4.

M53 EDGE TYPE CONTINUATION

Basic values for continuation mode are 1-4.

M54 EDGE TYPE INITIAL OFFSET

Basic values are $0.0-1.0$ (inclusive).

M55 RESTRICTED TEXT TYPE

Basic values are 2-6.

M56 RESTRICTED TEXT TYPE

The default value, 1, of this element is not allowed.

M57 RESTRICTED TEXT TYPE

This element shall appear in every version 3 metafile which uses RESTRICTED TEXT (either in each picture or in a METAFILE DEFAULTS REPLACEMENT element).

M58 Version 3 elements

The following elements are not allowed: TEXT SCORE TYPE, INTERPOLATED INTERIOR, SYMBOL LIBRARY INDEX, SYMBOL COLOUR, SYMBOL SIZE, SYMBOL ORIENTATION.

\subsection{Begment Elements}

M59 Global segments

When global segments are specified in the Metafile Descriptor, all global segment definitions shall follow all other Metafile Descriptor elements. 
M60 Global segments

When global segments are specified in the Picture Descriptor, all global segment definitions shall follow all other Picture Descriptor elements.

M61 COPY SEGMENT

Segment copy references shall not be nested more than 4 deep. Depth 1 shall correspond to flat structure (i.e., no nesting or hierarchy).

M62 COPY SEGMENT

Segment copy depth 1 shall correspond to flat structure (i.e., no nesting or hierarchy).

M63 SEGMENT PICK PRIORITY

This element has no graphical effect. It may be ignored by interpreters.

M64 Version 3 elements

The following elements are not allowed: CLIP INHERITANCE, SEGMENT HIGHLIGHTING.

\subsection{Escape Elements}

M65 Escape

No ESCAPE elements are allowed. (Those ESCAPE elements defined in MIL-D-28003 are no longer allowed.)

\subsection{External Elements}

\section{M66 MESSAGE}

The action required flag shall not be used to alter the picture definition.

\subsection{Generator Requirements}

M67 Generators shall create metafiles which accurately and correctly define the intended picture.

M68 Generators shall produce only conforming basic metafiles.

\subsection{Interpreter Requirements}

M69 Interpreters shall be classified as: Type 0 - monochrome; Type 1 - grayscale; or Type 2 - full color.

M70 Interpreters shall at a minimum, correctly interpret any conforming basic metafile of the same version and same type.

M71 The rendered picture shall accurately and correctly represent the metafile being interpreted. 
M72 Color shall be rendered according to the category of the interpreter: monochrome, grayscale, or color.

M73 If mapping of color or grayscale is allowed, the principles set forth in MIL-D-28003A shall apply. 


\section{APPENDIX A}

\section{ELEMENT ORDERING REQUIREMENTS \\ state List Tables}

The following tables are extracted from Iso 8632:1992. The tables show the required sequential relationships between metafile elements. The "states" in which each element is allowed for Version 1, Version 2, and Version 3 metafiles are described in the first table. This table also shows the lowest metafile version for which each element is defined. 
Table 8-CGM Elements by their allowed states

\begin{tabular}{|c|c|c|c|c|c|c|c|c|}
\hline \multirow{3}{*}{ CG.M Element } & \multirow{3}{*}{$\begin{array}{l}\text { ver } \\
\text { (1) }\end{array}$} & \multicolumn{7}{|c|}{ CG.11 Major States } \\
\hline & & PCS & MDS & $\begin{array}{l}\mathrm{DR} \\
(3)\end{array}$ & $\begin{array}{l}\text { GSS. } \\
\text { DSS }\end{array}$ & PDS & POS & LSS \\
\hline & & $v 1(2)$ & $v 1$ & $v 1$ & v2 & $v 1$ & v1 & $\sqrt{2}$ \\
\hline $\begin{array}{l}\text { BEGD METAFILE (4) } \\
\text { END METAFILE } \\
\text { BEGIN PICTLRE } \\
\text { BEGN PICTURE BODY } \\
\text { END PICTURE } \\
\end{array}$ & $\begin{array}{l}1 \\
1 \\
1 \\
1 \\
1\end{array}$ & $\begin{array}{l}X \\
x\end{array}$ & $\begin{array}{l}x \\
x\end{array}$ & & & $\mathrm{x}$ & $x$ & \\
\hline $\begin{array}{l}\text { BEGIN SEGMENT(7),v2 } \\
\text { BEGIN SEGMENT, } 3 \\
\text { END SEGMENT } \\
\text { BEGD FIGURE } \\
\text { END FIGURE } \\
\text { BEGIN PROTECTION REGION }\end{array}$ & $\begin{array}{l}2 \\
2 \\
2 \\
2 \\
2 \\
3\end{array}$ & & $\begin{array}{l}x \\
X\end{array}$ & & $\begin{array}{l}X \\
X \\
X\end{array}$ & $x$ & $\begin{array}{l}x \\
x \\
x \\
x\end{array}$ & $\begin{array}{l}x \\
x \\
x\end{array}$ \\
\hline $\begin{array}{l}\text { END PROTECTION REGION } \\
\text { BEGIN COMPOUND LINE } \\
\text { END COMPOUND LINE } \\
\text { BEGIN COMPOUND TEXT PATH } \\
\text { END COMPOUND TEXT PATH }\end{array}$ & $\begin{array}{l}3 \\
3 \\
3 \\
3 \\
3\end{array}$ & & & & $\begin{array}{l}x \\
x\end{array}$ & & $\begin{array}{l}x \\
x\end{array}$ & $\begin{array}{l}x \\
x\end{array}$ \\
\hline $\begin{array}{l}\text { BEGIN TILE ARRAY } \\
\text { END TILE ARRAY } \\
\text { METAFILE VERSION } \\
\text { METAFILE DESCRIPTION } \\
\text { VDCTYPE }\end{array}$ & $\begin{array}{l}3 \\
3 \\
1 \\
1 \\
1\end{array}$ & & $\begin{array}{l}x \\
X \\
X\end{array}$ & & & & $\bar{x}$ & \\
\hline $\begin{array}{l}\text { DNTEGER PRECISION } \\
\text { REAL PRECISION } \\
\text { LDEX PRECISION } \\
\text { COLOUR PRECISION } \\
\text { COLOUR NNDEX PRECISION } \\
\end{array}$ & $\begin{array}{l}1 \\
1 \\
1 \\
1 \\
1\end{array}$ & & $\begin{array}{l}\lambda \\
X \\
X \\
X \\
X\end{array}$ & & & & & \\
\hline $\begin{array}{l}\text { MAXTMUM COLOUR INDEX } \\
\text { COLOUR VALUE EXTENT } \\
\text { METAFILE ELEMENT LIST } \\
\text { METAFILE DEFAULTS REPLACEMENT } \\
\text { FONT LIST }\end{array}$ & $\begin{array}{l}1 \\
1 \\
1 \\
1 \\
1 \\
\end{array}$ & & $\begin{array}{l}\mathrm{X} \\
\mathrm{X} \\
\mathrm{X} \\
\mathrm{X} \\
\mathrm{X}\end{array}$ & & & & & \\
\hline $\begin{array}{l}\text { CHARACTER SET LIST } \\
\text { CHARACTER CODING ANNOUNCER } \\
\text { NAME PRECISION } \\
\text { MAXIMUM VDC EXTENT } \\
\text { SEGMENT PRIORTYY EXTENT }\end{array}$ & $\begin{array}{l}1 \\
1 \\
2 \\
2 \\
2\end{array}$ & & $\begin{array}{l}X \\
X \\
X \\
X \\
X\end{array}$ & & & & & \\
\hline $\begin{array}{l}\text { COLOUR MODEL } \\
\text { COLOUR CALIBRATION } \\
\text { FONT PROPERTIES } \\
\text { GLYPH MAPPING } \\
\text { SYMBOL LIBRARY LIST }\end{array}$ & $\begin{array}{l}3 \\
3 \\
3 \\
3 \\
3\end{array}$ & & $\begin{array}{l}\mathrm{X} \\
\mathrm{X} \\
\mathrm{X} \\
\mathrm{X} \\
\mathrm{X}\end{array}$ & & & & & \\
\hline
\end{tabular}


Table 8- CGM Elements by their allowed states (continued)

\begin{tabular}{|c|c|c|c|c|c|c|c|c|}
\hline & & \multicolumn{7}{|c|}{ CG.11 Wlajor States } \\
\hline \multirow[t]{2}{*}{ CGM Element } & \multirow{2}{*}{$\begin{array}{l}\text { vet } \\
\text { (1) }\end{array}$} & PCS & MDS & $\begin{array}{l}\mathrm{DR} \\
\text { (3) }\end{array}$ & $\begin{array}{l}\text { GSS, } \\
\text { DSS }\end{array}$ & PDS & POS & LSS \\
\hline & & $\mathrm{v} 1(2)$ & $\mathrm{v} 1$ & v1 & v2 & v1 & v1 & $\mathrm{v} 2$ \\
\hline SCALING MODE & 1 & & & $\mathrm{x}$ & & $\mathrm{x}$ & & \\
\hline COLOUR SELECTION MODE(7), v1 & 1 & & & $\mathrm{x}$ & & $\mathrm{x}$ & & \\
\hline COLOUR SELECTION MC & 1 & & & $\mathrm{x}$ & $\mathrm{x}$ & $\mathrm{x}$ & $\mathrm{x}$ & $\mathrm{x}$ \\
\hline LINE WIDTH SPECIFICATION MODE(7), v1 & 1 & & & $\mathrm{x}$ & & $\mathrm{x}$ & & \\
\hline LDNE WIDTH SPECIFCATION MODE, V2/3 & 1 & & & $\mathrm{x}$ & $\mathrm{x}$ & $\mathrm{x}$ & $\mathrm{x}$ & \\
\hline MARKER SZE SPECIFCATION MODE(7), v1 & 1 & & & $\mathrm{x}$ & & $\bar{x}$ & & \\
\hline MARKER SZZE SPECIFICATION MODE, v $2 \beta$ & 1 & & & $\mathrm{x}$ & $\mathrm{x}$ & $\mathrm{x}$ & $\mathrm{x}$ & $\mathrm{x}$ \\
\hline EDGE WDTH SPECIFCATION MODE(7), v1 & 1 & & & $\mathrm{x}$ & & $\mathrm{x}$ & & \\
\hline EDGE WIDTH SPECIFICATION MODE, v $2 \beta$ & 1 & & & $\mathrm{x}$ & $\mathrm{x}$ & $\mathrm{x}$ & $\mathrm{x}$ & $\mathrm{x}$ \\
\hline VDC EXTENT & 1 & & & & & & & \\
\hline BACKGROUND COLOUR & 1 & & & $\mathrm{x}$ & & $\mathrm{X}$ & & \\
\hline DEVTCE VTEWPORT & 2 & & & $\mathrm{x}$ & & $\mathrm{x}$ & & \\
\hline DEVICE VIEWPORT MAPPING & 2 & & & $\mathrm{x}$ & & $\mathrm{x}$ & & \\
\hline CIFICATION MODE & 2 & & & $\mathrm{x}$ & & $x$ & & \\
\hline LINE REPRESENTATION & 2 & & & $\mathrm{x}$ & & $\mathrm{x}$ & & \\
\hline MARKER REPRESENTATION & 2 & & & $x$ & & $\bar{x}$ & & \\
\hline TEXT REPRESENTATION & 2 & & & $\mathrm{x}$ & & $\mathrm{x}$ & & \\
\hline FLL REPRESENTATTON & 2 & & & $\mathrm{x}$ & & $\mathrm{x}$ & & \\
\hline EDGE REPRESENTAT & 2 & & & $\mathrm{x}$ & & $\mathrm{x}$ & & \\
\hline NTERIOR STYLE SPECIFCATION MODE & 3 & & & $\mathrm{x}$ & $\mathrm{x}$ & $\mathrm{x}$ & $\mathrm{x}$ & $x$ \\
\hline LLNE AND EDGE TYPE DEFLNTION & 3 & & & $\mathrm{x}$ & & $\mathrm{x}$ & & \\
\hline HATCH STYLE DEFITTION & 3 & & & $\mathrm{x}$ & & $\mathrm{x}$ & & \\
\hline GEOMETRIC PATTERN DEFNTTION & 3 & & & $x$ & & & & \\
\hline VDC NTTEGER PRECISION & 1 & & & $\mathrm{x}$ & $\mathrm{x}$ & & $\mathrm{x}$ & $\mathrm{x}$ \\
\hline VDC REAL PRECISION & 1 & & & $\mathrm{x}$ & $\mathrm{x}$ & & $\mathrm{x}$ & $\mathrm{x}$ \\
\hline ALXILIARY COLOUR & 1 & & & $\mathrm{x}$ & $\bar{x}$ & & $\mathrm{X}$ & $x$ \\
\hline TRAVSPARENCY & 1 & & & $\mathrm{x}$ & $\mathrm{x}$ & & $\mathrm{x}$ & $\mathrm{x}$ \\
\hline CLIP RECTANGLE & 1 & & & $\mathrm{x}$ & $\mathrm{x}$ & & $\mathrm{x}$ & $\mathrm{x}$ \\
\hline CLIP DNDICATOR & 1 & & & $\mathrm{x}$ & $\mathrm{x}$ & & $\mathrm{x}$ & $\mathrm{x}$ \\
\hline LRE CLIPPLNG MODE & 2 & & & $\mathrm{x}$ & $\mathrm{x}$ & & $\mathrm{x}$ & $\mathrm{x}$ \\
\hline MARKER CLIPPING MODE & 2 & & & $\mathrm{x}$ & $\bar{x}$ & & $\mathrm{x}$ & $\bar{x}$ \\
\hline EDGE CLIPPENG MODE & 2 & & & $\mathrm{x}$ & $\mathrm{x}$ & & $\mathrm{x}$ & $\mathrm{x}$ \\
\hline NEW REGION & 2 & & & & & & & \\
\hline SAVE PRLMTTIVE CONTEXT & 2 & & & & $\mathrm{x}$ & & $\mathrm{x}$ & $\mathrm{x}$ \\
\hline RESTORE PRIMITIVE CONTEXT & 2 & & & & $\mathrm{x}$ & & $\mathrm{x}$ & $x$ \\
\hline PROTECTION REGION LNDICATOR & 3 & & & $\bar{x}$ & $\mathrm{x}$ & & $\mathrm{x}$ & $\bar{x}$ \\
\hline GENERALIZED TEXT PATH MODE & 3 & & & $\mathrm{x}$ & $\mathrm{x}$ & & $\mathrm{x}$ & \\
\hline MITRE LIMTT & 3 & & & $\mathrm{x}$ & $\mathrm{x}$ & & $\mathrm{x}$ & $x$ \\
\hline TRANSPARENT CELL COLOUR & 3 & & & $\mathrm{x}$ & $\mathrm{x}$ & $\mathrm{x}$ & $\mathrm{x}$ & \\
\hline
\end{tabular}


Table 8-CG.M Elements by their allowed states (continued)

\begin{tabular}{|c|c|c|c|c|c|c|c|c|}
\hline \multirow{3}{*}{ CG.M Element } & \multirow{3}{*}{$\begin{array}{l}\text { ver } \\
\text { (1) }\end{array}$} & \multicolumn{7}{|c|}{ Co.g! .12jor States } \\
\hline & & PCS & MDS & $\begin{array}{l}D R \\
\text { (3) }\end{array}$ & $\begin{array}{l}\text { GSS, } \\
\text { DSS }\end{array}$ & PDS & POS & LSS \\
\hline & & $v 1(2)$ & v1 & $\mathrm{vl}$ & $\mathrm{v2}$ & $\mathrm{v} 1$ & $\mathrm{v1}$ & $\sqrt{2}$ \\
\hline $\begin{array}{l}\text { POLYILNE } \\
\text { DISIONT POLYZNE }\end{array}$ & 1 & & & & $\begin{array}{l}\mathrm{X} \\
\mathrm{x}\end{array}$ & & $\bar{x}$ & $\bar{X}$ \\
\hline $\begin{array}{l}\text { DISJONT POL YLINE } \\
\text { POLYMARKER }\end{array}$ & 1 & & & & $x$ & & $\begin{array}{l}x \\
x\end{array}$ & $\begin{array}{l}x \\
x\end{array}$ \\
\hline $\begin{array}{l}\text { POLYMARKER } \\
\text { TEXT }\end{array}$ & 1 & & & & $\hat{x}$ & & $\hat{x}$ & $\hat{x}$ \\
\hline RESTRICTED TEXT & 1 & & & & $\mathrm{x}$ & & $\mathrm{x}$ & $\mathrm{x}$ \\
\hline APPEND TEXT & 1 & & & & & & & \\
\hline POLYGON & 1 & & & & $\mathrm{X}$ & & $\mathrm{x}$ & $\mathrm{x}$ \\
\hline POLYGON SET & 1 & & & & $\mathrm{X}$ & & $\mathrm{x}$ & $x$ \\
\hline $\begin{array}{l}\text { CELL ARRAY } \\
\text { GDP }\end{array}$ & $\begin{array}{l}1 \\
1\end{array}$ & & & & $\begin{array}{l}X \\
x\end{array}$ & & $\begin{array}{l}x \\
x\end{array}$ & $\begin{array}{l}x \\
x\end{array}$ \\
\hline RECTANGLE & 1 & & & & $\bar{x}$ & & $\bar{x}$ & $\bar{x}$ \\
\hline CIRCLE & 1 & & & & $\mathrm{x}$ & & $\mathrm{x}$ & $\mathrm{x}$ \\
\hline CIRCULAR ARC 3 POINT & 1 & & & & $\mathrm{x}$ & & $\mathrm{x}$ & $\mathrm{x}$ \\
\hline CIRCULAR ARC 3 POINT CLOSE & 1 & & & & $\mathrm{x}$ & & $\mathrm{x}$ & $\mathrm{x}$ \\
\hline CIRCULAR ARC CENTRE & 1 & & & & $\mathrm{x}$ & & $\mathrm{x}$ & $x$ \\
\hline CIRCULAR ARC CENTRE CLOSE & 1 & & & & $\bar{x}$ & & $\bar{X}$ & $\bar{X}$ \\
\hline ELLIPSE & 1 & & & & $\mathrm{x}$ & & $\mathrm{x}$ & $\mathrm{x}$ \\
\hline ELLIPTICAL ARC & 1 & & & & $\mathrm{x}$ & & $\mathrm{x}$ & $\mathrm{x}$ \\
\hline ELLPTICAL ARC CLOSE & 1 & & & & $\mathrm{x}$ & & $\mathrm{x}$ & $x$ \\
\hline CIRCULAR ARC CENTRE REVERSED & 2 & & & & $\mathrm{x}$ & & $\mathrm{x}$ & $\mathrm{x}$ \\
\hline CONNECTLIG EDGE & 2 & & & & & & & \\
\hline HYPERBOLIC ARC & 3 & & & & $\mathrm{x}$ & & & $\mathrm{x}$ \\
\hline PARABOLIC ARC & 3 & & & & $\mathrm{x}$ & & $\mathrm{x}$ & $\mathrm{x}$ \\
\hline NON.UNTFORM B.SPLLVE & 3 & & & & $\mathrm{x}$ & & $\mathrm{x}$ & $\mathrm{x}$ \\
\hline NON-UNIFORM RATIONAL B.SPLLNE & 3 & & & & $\mathrm{x}$ & & $\mathrm{x}$ & $\mathrm{x}$ \\
\hline POLYBEZIER & 3 & & & & $\mathrm{X}$ & & $\bar{X}$ & $\bar{x}$ \\
\hline POLYS YMBOL & 3 & & & & $\mathrm{x}$ & & $\mathrm{x}$ & $\mathrm{x}$ \\
\hline BTTONAL TLE & 3 & & & & & & & \\
\hline TILE & 3 & & & & & & & \\
\hline LINE BLNDLE ENDEX & 1 & & & $\mathrm{x}$ & $\mathrm{x}$ & & $\mathrm{x}$ & $x$ \\
\hline LINE TYPE & 1 & & & $\bar{x}$ & $\bar{x}$ & & $\bar{x}$ & $\bar{x}$ \\
\hline LINE WIDTH & 1 & & & $\mathrm{x}$ & $\mathrm{x}$ & & $\mathrm{x}$ & $\mathrm{x}$ \\
\hline LNE COLOUR & 1 & & & $x$ & $\mathrm{x}$ & & $\mathrm{x}$ & $\mathrm{x}$ \\
\hline MARKER BUNDLE INDEX & 1 & & & $\mathrm{x}$ & $\mathrm{x}$ & & $\mathrm{x}$ & $\mathrm{x}$ \\
\hline MARKER TYPE & 1 & & & $\mathrm{x}$ & $\mathrm{x}$ & & $\mathrm{x}$ & $x$ \\
\hline MARKER SZE & 1 & & & $\bar{x}$ & $\bar{x}$ & & $\bar{X}$ & $\bar{x}$ \\
\hline MARKER COLOUR & 1 & & & $\mathrm{x}$ & $\mathrm{x}$ & & $\mathrm{x}$ & $\mathrm{x}$ \\
\hline TEXT BLNDLE DNDEX & 1 & & & $\mathrm{x}$ & $\mathrm{x}$ & & $\mathrm{x}$ & $\mathrm{x}$ \\
\hline TEXT FONT DNDEX & 1 & & & $\mathrm{x}$ & $\mathrm{x}$ & & $\mathrm{x}$ & $\mathrm{x}$ \\
\hline TEXT PRECISION & 1 & & & $x$ & $\mathrm{x}$ & & $\mathrm{x}$ & $\mathrm{x}$ \\
\hline CHARACTER EXPANSION FACTOR & 1 & & & $\bar{x}$ & $\bar{x}$ & & $\bar{x}$ & $\bar{x}$ \\
\hline CHARACTER SPACDNG & 1 & & & $\mathrm{x}$ & $\mathrm{x}$ & & $x$ & $x$ \\
\hline TEXT COLOUR & 1 & & & $\mathrm{x}$ & $\mathrm{x}$ & & $\mathrm{x}$ & $\mathrm{x}$ \\
\hline CHARACTER HEIGHT & 1 & & & $x$ & $\mathrm{x}$ & & $x$ & $\mathrm{x}$ \\
\hline CHARACTER ORIENTATTON & 1 & & & $\mathrm{x}$ & $x$ & & $x$ & $\mathrm{x}$ \\
\hline
\end{tabular}


Table 8 - CGM Elements by their allowed states (continued)

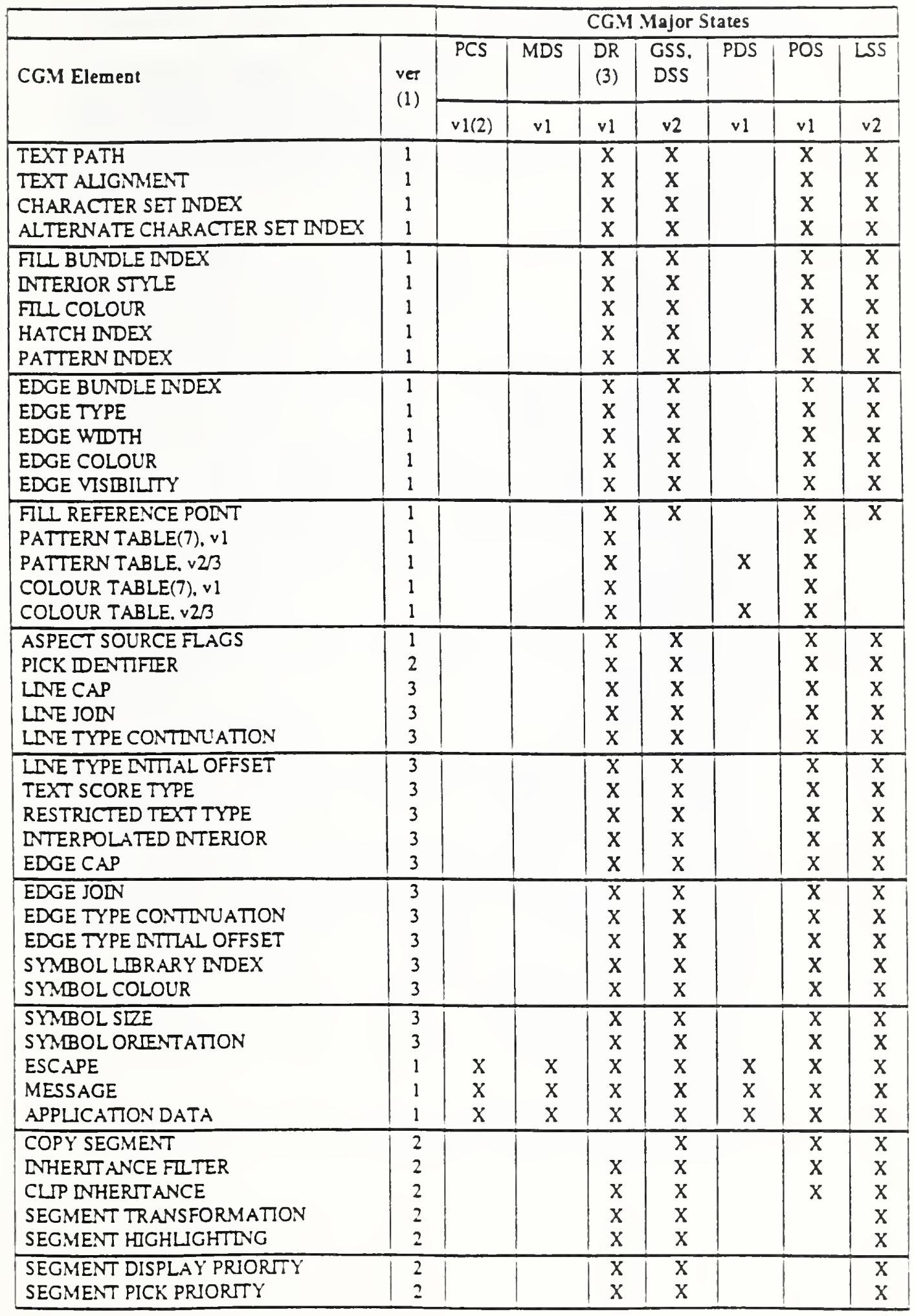


Table 8 - CGM Elements by their allowed states (continued)

\begin{tabular}{|c|c|c|c|c|c|}
\hline & \multicolumn{5}{|c|}{ CG.M Minor States } \\
\hline CG.M Element & $\begin{array}{l}\text { FOS } \\
\text { v2 }\end{array}$ & $\begin{array}{c}\text { TOS } \\
\text { v1 }\end{array}$ & $\begin{array}{c}\text { CPS } \\
\text { v3 }\end{array}$ & $\begin{array}{c}\text { PRS } \\
\text { v3 }\end{array}$ & $\begin{array}{c}\text { TAS } \\
\text { v3 }\end{array}$ \\
\hline $\begin{array}{l}\text { BEGIN METAFILE } \\
\text { END METAFILE } \\
\text { BEGIN PICTURE } \\
\text { BEGIN PICTURE BODY } \\
\text { END PICTURE } \\
\end{array}$ & & & & & \\
\hline $\begin{array}{l}\text { BEGIN SEGMENT } \\
\text { END SEGMENT } \\
\text { BEGIN FIGURE } \\
\text { END FIGURE } \\
\text { BEGIN PROTECTION REGION } \\
\end{array}$ & $\mathrm{x}$ & & & - & \\
\hline $\begin{array}{l}\text { END PROTECTION REGION } \\
\text { BEGN COMPOUND LNE } \\
\text { END COMPOUND LINE } \\
\text { BEGIN COMPOUND TEXT PATH } \\
\text { END COMPOUND TEXT PATH } \\
\end{array}$ & & & $\begin{array}{l}X(5) \\
X(6)\end{array}$ & $\bar{x}$ & \\
\hline $\begin{array}{l}\text { BEGIN TILE ARRAY } \\
\text { END TLE ARRAY } \\
\text { METAFLE VERSION } \\
\text { METAFLE DESCRPTION } \\
\text { VDC TYPE } \\
\end{array}$ & & & & & $\mathrm{x}$ \\
\hline $\begin{array}{l}\text { INTEGER PRECISION } \\
\text { REAL PRECISION } \\
\text { DNDEX PRECISION } \\
\text { COLOUR PRECISION } \\
\text { COLOUR INDEX PRECISION }\end{array}$ & & & & & \\
\hline $\begin{array}{l}\text { MAXIMUM COLOUR NNDEX } \\
\text { COLOUR VALUE EXTENT } \\
\text { METAFLE ELEMENT LIST } \\
\text { METAFLE DEFAULTS REPLACEMENT } \\
\text { FONT LIST }\end{array}$ & & & & & \\
\hline $\begin{array}{l}\text { CHARACTER SET LIST } \\
\text { CHARACTER CODING ANNOUNCER } \\
\text { NAME PRECISION } \\
\text { MAXIMUM VDC EXTENT } \\
\text { SEGMENT PRIORTY EXTENT }\end{array}$ & & & & & \\
\hline $\begin{array}{l}\text { COLOUR MODEL } \\
\text { COLOUR CALIBRATION } \\
\text { FONT PROPERTIES } \\
\text { GLYPH MAPPING } \\
\text { SYMBOL LIBRARY LIST } \\
\end{array}$ & & & & & \\
\hline
\end{tabular}


Tabie 8 - CGM Elements by their allowed states (continued)

\begin{tabular}{|c|c|c|c|c|c|}
\hline & \multicolumn{5}{|c|}{ CG.M Minor Stutes } \\
\hline CG.M Element & $\begin{array}{c}\text { FOS } \\
\mathrm{v} 2\end{array}$ & $\begin{array}{c}\text { TOS } \\
\text { v1 }\end{array}$ & $\begin{array}{c}\text { CPS } \\
v 3\end{array}$ & $\begin{array}{l}\text { PRS } \\
\text { v3 }\end{array}$ & $\begin{array}{c}\text { TAS } \\
\text { v3 }\end{array}$ \\
\hline $\begin{array}{l}\text { SCALING MODE } \\
\text { COLOUR SELECTION MODE } \\
\text { LNE WDTH SPECIFCATION MODE } \\
\text { MARKER SUZE SPECIFCATION MODE } \\
\text { EDGE WIDTH SPECIFCATION MODE }\end{array}$ & & & & & \\
\hline $\begin{array}{l}\text { VDC EXTENT } \\
\text { BACKGROUND COLOUR } \\
\text { DEYCE VIEWPORT } \\
\text { DEVICE VIEWPORT MAPPING } \\
\text { DEYCE VIEWPORT SPECIFCATION MODE }\end{array}$ & & & & & \\
\hline $\begin{array}{l}\text { LLNE REPRESENTATION } \\
\text { MARKER REPRESENTATION } \\
\text { TEXT REPRESENTATION } \\
\text { FILLREPRESENTATION } \\
\text { EDGE REPRESENTATION }\end{array}$ & & & & & \\
\hline $\begin{array}{l}\text { INTERIOR STYLE SPECIFICATION MODE } \\
\text { LINE AND EDGE TYPE DEFLTTION } \\
\text { HATCH STYLE DEFINTION } \\
\text { GEOMETRIC PATTERN DEFITION } \\
\text { VDC DTEGER PRECISION }\end{array}$ & $\mathrm{x}$ & & $\mathrm{x}$ & $\mathrm{x}$ & \\
\hline $\begin{array}{l}\text { VDC REAL PRECISION } \\
\text { AUXIIARY COLOUR } \\
\text { TRANSPARENCY } \\
\text { CLIP RECTANGLE } \\
\text { CLIP INDICATOR } \\
\end{array}$ & $\begin{array}{l}X \\
X \\
X\end{array}$ & $\begin{array}{l}X \\
X\end{array}$ & $\bar{x}$ & $\bar{X}$ & \\
\hline $\begin{array}{l}\text { LNNE CLIPPING MODE } \\
\text { MARKER CLIPPING MODE } \\
\text { EDGE CLIPPLNG MODE } \\
\text { NEW REGION } \\
\text { SAVE PRLMTTVE CONTEXT }\end{array}$ & $\mathrm{x}$ & & & $\mathrm{X}$ & \\
\hline $\begin{array}{l}\text { RESTORE PRLWITIVE CONTEXT } \\
\text { PROTECTION REGION DNDICATOR } \\
\text { GENERALIZED TEXT PATH MODE } \\
\text { MITRE LIMITT } \\
\text { TRANSPARENT CELL COLOUR }\end{array}$ & & & & & \\
\hline
\end{tabular}


Table 8-CGM Elements by their allowed states (continued)

\begin{tabular}{|c|c|c|c|c|c|}
\hline & & CG.1 & Ginor & tates & \\
\hline CG.M Element & $\begin{array}{c}\text { FOS } \\
\text { v2 }\end{array}$ & $\begin{array}{c}\text { TOS } \\
\text { v1 }\end{array}$ & $\begin{array}{c}\text { CPS } \\
\mathrm{v} 3\end{array}$ & $\begin{array}{c}\text { PRS } \\
\text { v3 }\end{array}$ & $\begin{array}{c}\text { TAS } \\
\text { v3 }\end{array}$ \\
\hline $\begin{array}{l}\text { POLYLNE } \\
\text { DISIONT POLYLNEE } \\
\text { POLYMARKER } \\
\text { TEXT } \\
\text { RESTRICTED TEXT } \\
\end{array}$ & $\begin{array}{l}\bar{X} \\
X\end{array}$ & & $\begin{array}{l}\bar{X} \\
x\end{array}$ & $\begin{array}{l}\bar{X} \\
X\end{array}$ & \\
\hline $\begin{array}{l}\text { APPEND TEXT } \\
\text { POLYGON } \\
\text { POLYGON SET } \\
\text { CELL ARRAY } \\
\text { GDP }\end{array}$ & $\begin{array}{l}\mathrm{X} \\
\mathrm{X} \\
\mathrm{X}\end{array}$ & $\overline{\mathrm{X}}$ & $x$ & $\begin{array}{l}X \\
X\end{array}$ & \\
\hline $\begin{array}{l}\text { RECTANGLE } \\
\text { CIRCLE } \\
\text { CIRCULAR ARC } 3 \text { POINT } \\
\text { CIRCULAR ARC } 3 \text { POINT CLOSE } \\
\text { CIRCULAR ARC CENTRE }\end{array}$ & $\begin{array}{l}\mathrm{X} \\
\mathrm{X} \\
\mathrm{X} \\
\mathrm{X} \\
\mathrm{X}\end{array}$ & & $\mathrm{X}$ & $\begin{array}{l}\mathrm{X} \\
\mathrm{X} \\
\mathrm{X} \\
\mathrm{X} \\
\mathrm{X}\end{array}$ & \\
\hline $\begin{array}{l}\text { CIRCULAR ARC CENTRE CLOSE } \\
\text { ELLIPSE } \\
\text { ELLIPTICAL ARC } \\
\text { ELLIPTICAL ARC CLOSE } \\
\text { CIRCULAR ARC CENTRE REVERSED }\end{array}$ & $\begin{array}{l}\mathrm{X} \\
\mathrm{X} \\
\mathrm{X} \\
\mathrm{X} \\
\mathrm{X}\end{array}$ & & $\mathrm{X}$ & $\begin{array}{l}\mathrm{X} \\
\mathrm{X} \\
\mathrm{X} \\
\mathrm{X} \\
\mathrm{X}\end{array}$ & \\
\hline $\begin{array}{l}\text { CONNECTING EDGE } \\
\text { HYPERBOLIC ARC } \\
\text { PARABOLIC ARC } \\
\text { NON.UNIFORM B.SPLINE } \\
\text { NON.UNIFORM RATIONAL B.SPLINE }\end{array}$ & $\begin{array}{l}\mathrm{X} \\
\mathrm{x} \\
\mathrm{x} \\
\mathrm{x} \\
\mathrm{x}\end{array}$ & & $\begin{array}{l}X \\
X \\
X \\
X\end{array}$ & $\begin{array}{l}X \\
X \\
X \\
X\end{array}$ & \\
\hline $\begin{array}{l}\text { POLYBEZIER } \\
\text { POLYSYMBOL } \\
\text { BTONAL TILE } \\
\text { TILE } \\
\text { LINE BUNDLE INDEX }\end{array}$ & $\bar{x}$ & & $\bar{X}$ & $\bar{x}$ & $\begin{array}{l}X \\
X\end{array}$ \\
\hline $\begin{array}{l}\text { LDE TYPE } \\
\text { LDE WIDTH } \\
\text { LNE COLOUR } \\
\text { MARKER BUNDLE DNDEX } \\
\text { MARKER TYPE } \\
\end{array}$ & & & & & \\
\hline $\begin{array}{l}\text { MARKER SIZE } \\
\text { MARKER COLOUR } \\
\text { TEXT BUNDLE INDEX } \\
\text { TEXT FONT INDEX } \\
\text { TEXT PRECISION } \\
\end{array}$ & & $\begin{array}{l}X \\
X \\
X\end{array}$ & & & \\
\hline $\begin{array}{l}\text { CHARACTER EXPANSION FACTOR } \\
\text { CHARACTER SPACDNG } \\
\text { TEXT COLOUR } \\
\text { CHARACTER HEIGHT } \\
\text { CHARACTER ORIENTATION }\end{array}$ & & $\begin{array}{l}\bar{X} \\
X \\
X \\
X\end{array}$ & & & \\
\hline
\end{tabular}


Table 8 - CGM Elements by their allowed states (concluded)

\begin{tabular}{|c|c|c|c|c|c|}
\hline & \multicolumn{5}{|c|}{ CG.H .Minor States } \\
\hline CG.M Element & $\begin{array}{c}\text { FOS } \\
\text { v2 }\end{array}$ & $\begin{array}{c}\text { TOS } \\
\text { v1 }\end{array}$ & $\begin{array}{c}\text { CPS } \\
\text { v3 }\end{array}$ & $\begin{array}{c}\text { PRS } \\
\text { v3 }\end{array}$ & $\begin{array}{c}\text { TAS } \\
\text { v3 }\end{array}$ \\
\hline $\begin{array}{l}\text { TEXT PATH } \\
\text { TEXT ALIGNMENT } \\
\text { CHARACTER SET INDEX } \\
\text { ALTERNATE CHARACTER SET INDEX }\end{array}$ & & $\begin{array}{l}X \\
X\end{array}$ & & & \\
\hline $\begin{array}{l}\text { FILL BUNDLE INDEX } \\
\text { INTERIOR STYLE } \\
\text { FLL COLOUR } \\
\text { HATCH INDEX } \\
\text { PATTERN INDEX } \\
\end{array}$ & & & & & \\
\hline $\begin{array}{l}\text { EDGE BUNDLE INDEX } \\
\text { EDGE TYPE } \\
\text { EDGE WIDTH } \\
\text { EDGE COLOUR } \\
\text { EDGE VISIBILITY } \\
\end{array}$ & $\begin{array}{l}\mathrm{X} \\
\mathrm{x} \\
\mathrm{x} \\
\mathrm{x} \\
\mathrm{X} \\
\end{array}$ & & & & \\
\hline $\begin{array}{l}\text { FIL REFERENCE POINT } \\
\text { PATTERN TABLE } \\
\text { COLOUR TABLE } \\
\text { ASPECT SOURCE FLAGS } \\
\text { PICK IDENTIFIER } \\
\end{array}$ & $x$ & & & & \\
\hline $\begin{array}{l}\text { LINE CAP } \\
\text { LNE JONN } \\
\text { LNE TYPE CONTINUATION } \\
\text { LINE TYPE INTIIAL OFFSET } \\
\text { TEXT SCORE TYPE }\end{array}$ & & $x$ & & & \\
\hline $\begin{array}{l}\text { RESTRCTED TEXT TYPE } \\
\text { INTERPOLATED INTERIOR } \\
\text { EDGE CAP } \\
\text { EDGE JONN } \\
\text { EDGE TYPE CONTINUATION }\end{array}$ & & & & & \\
\hline $\begin{array}{l}\text { EDGE TYPE INTTLAL OFFSET } \\
\text { SYMBOL LIBRARY INDEX } \\
\text { SYMBOL COLOUR } \\
\text { SYMBOL SIZE } \\
\text { SYMBOL ORIENTATION }\end{array}$ & & & & & \\
\hline $\begin{array}{l}\text { ESCAPE } \\
\text { MESSAGE } \\
\text { APPLICATION DATA } \\
\text { COPY SEGMENT } \\
\text { DNHERTTANCE FILTER }\end{array}$ & $\begin{array}{l}\mathrm{X} \\
\mathrm{x} \\
\mathrm{X}\end{array}$ & $\bar{x}$ & $\begin{array}{l}\bar{X} \\
x \\
x\end{array}$ & $\begin{array}{l}\bar{x} \\
x \\
x\end{array}$ & $\begin{array}{l}X \\
X \\
X\end{array}$ \\
\hline $\begin{array}{l}\text { CLIP DNHERTANCE } \\
\text { SEGMENT TRANSFORMATION } \\
\text { SEGMENT HIGHLIGHTLNG } \\
\text { SEGMENT DISPLAY PRIORTY } \\
\text { SEGMENT PICK PRIORTTY }\end{array}$ & & & & & \\
\hline
\end{tabular}

Notes on the state tables:

1. The "ver" column in the tables indicates the lowest mewfile version tn which the element may appear.

2. These entries define the lowest metafile version for which this state is defined. Therefore " $v$ " indicates the state is defined for Version 1 metafiles (hence also for V'crston 2 and Version 3 metafiles): "v2" indicates that the state is defined for Version 2 metafiles (hence also for Version 3); and " $v 3$ " indicates that the state is defincd only for V'ersion 3 metafiles. 
3. Defaulis replacement mode is not really a metafile state, but for implementation purposes it behaves as one and so has been uncluded in this table.

4. The Metafile Closed State is not included in this table - BEGIN METAFILE is the only element allowed in this state.

5. END COMPOUND LINE is only allowed in Compound Path State when that state was entered by the BEGIN COMPOUND LINE elemenL

6. END COMPOUND TEXT PATH is only allowed in Compound Path State when that sute was entered by the BEGIN COMPOUND TEXT PATH element.

7. These elements have state rules which are different depending upon the metafile version. For example, COLOUR TABLE is not allowed in the picture body in Version 1 metafiles, but it is allowed in the picture body in Version 2 and Version 3 metafiles.

Major States :

PCS Picrure Closed State

MDS Metafile Descriptor State

DR Defaults Replacement Mode

GSS Global Segment State

DSS Picure Descriptor Segment State

PDS Picure Descriptor State-

POS Picture Open State

LSS Local Segment State

inor States:

FOS Figure Open State

TOS Text Open State

CPS Compound Path State

PRS Protection Region State

TAS Tile Array State 
Table 9-CGM state transitions into and out of minor states

\begin{tabular}{|l|l|l|}
\hline Element & Original state & Final state \\
\hline BEGIN FGURE & GSS,LSS,POS & $\begin{array}{l}\text { FOS } \\
\text { END FIGURE }\end{array}$ \\
FOS & previous state \\
\hline TEXT (not-final) & GSS,LSS,POS & TOS \\
RESTRICTED TEXT (not-Gnal) & GSS,LSS,POS & TOS \\
pPPEND TEXT (final) & TOS & previous state \\
\hline BEGIN COMPOUND LINE & GSS,LSS,POS & CPS \\
END COMPOUND LINE & CPS & previous state \\
BEGIN COMPOUND IEXT PATH & GSS,LSS,POS & CPS \\
END COMPOUND TEXT PATH & CPS & previous state \\
\hline BEGIN PROTECTION REGION & GSS,LSS,POS & PRS \\
END PROTECTION REGION & PRS & previous statc \\
\hline BEGIN TILE ARRAY & POS & TAS \\
END TILE ARRAY & TAS & previous statc \\
\hline
\end{tabular}



